\title{
Unplayed Galant Melodies, the Ubiquity of the Rarest Interval, and the Heyday of the Major Mode[1]
}

\author{
GILAD RABINOVITCH[2] \\ Florida State University
}

\begin{abstract}
This article examines in a preliminary fashion the potential connections between the usage of Gjerdingen's $(1988,2007)$ skeletal galant schemata, the heyday of the major mode during the period 1750-1799 (Albrecht \& Huron, 2014; Horn \& Huron, 2015), and the rare intervals of the diatonic set (Browne, 1981). I discuss the relations between the rarity of the tritone and semitone in the diatonic template and in musical usage (Huron 2006, 2008; David Temperley, personal communication, 2017). I hypothesize that the skeletal usage of schemata emphasizes rare intervals (tritone and semitone) respective to their common counterparts. Though this is predominantly an armchair, speculative inquiry, a preliminary pilot analysis of a small expert-annotated corpus from Gjerdingen (2007) provides tentative support for the hypothesis that the skeletal usage of schemata overemphasizes vertical tritones, but not melodic semitones. The prevalence of skeletal tritones in the schemata abstracted by Gjerdingen suggests that the process of abstraction is associated with finding unambiguous cues for a local tonal context. While the present article relies on Gjerdingen's expert analytical annotations of a small corpus and extraction of a contrapuntal skeleton, I conclude by offering hypotheses for future testing regarding the increased prevalence and salience of tritones on the musical surface in the period 17501799 , a subset of common-practice tonality.
\end{abstract}

Submitted 2017 September 18; accepted 2019 July 15.

Published 2020 July 6; https://doi.org/10.18061/emr.v14i3-4.6070

KEYWORDS: galant schemata, eighteenth-century music, diatonic set, tonality, pitch reduction

\section{BACKGROUND: HOW RARE ARE RARE INTERVALS? HOW MAJOR IS THE MAJOR MODE?}

THIS article deals with a particularly elusive object for observation: the skeletal tones associated with Robert Gjerdingen's $(1988,2007)$ galant schemata. I cautiously write "skeletal tones associated with" the schemata rather than referring to "the" schemata, since the schemata are multi-parametric and include metric, harmonic (or contrapuntal), and ornamental features beyond their soprano-and-bass skeletons. For the purpose of this article, I am particularly interested in the soprano skeletal threads that undercut the melodic surface of eighteenth-century music, as well as the intervals that they form with the skeletal bass. Gjerdingen defines his outer-voice skeletons as scale degrees respective to a local tonic: historical approaches to tonality suggest that every tonal shift that we might think of as a "tonicization" was conceptualized as a wholesale shift to a different tonal center (Lester, 1992; Gjerdingen, 2007; Byros, 2009; Holtmeier, 2011). By analyzing the musical surface, Gjerdingen abstracts a soprano-and-bass contrapuntal skeleton and identifies local key contexts. For instance, the soprano skeleton of the Fonte schema (Example 1, Appendix C) is annotated as [ii]: ${ }^{\wedge} 4-^{\wedge} 3[b]$ followed by $[I]:{ }^{\wedge} 4-^{\wedge} 3$, not monotonally $\left({ }^{\wedge} 5-^{\wedge} 4-\wedge 4-\wedge 3\right)$. Thus, Gjerdingen’s annotations represent both an abstraction of an outer-voice skeleton from the musical surface as well as the local key context or key contexts. Though my present inquiry analyzes Gjerdingen's expert annotations of a corpus of 14 pieces, my assumption is that Gjerdingen reacts to melodically salient events in the style and their typical configurations, such as the Fonte schema of Example 1. In other words, I assume that the present inquiry is not merely a study of the idiosyncrasies of a single scholar's analytical technique, but rather has potential 
implications for understanding the growing prevalence and salience of tritone resolutions in eighteenthcentury music.

Though this is an armchair theoretical inquiry with some pilot results, I will conclude by proposing hypotheses that can be operationalized and tested in the future by evaluating the musical surface directly. After presenting some theoretical considerations, I will provide a pilot account of schemata based on the expert-annotated corpus of full-piece analyses in Gjerdingen (2007). To my knowledge, this is virtually the only corpus annotated by an expert analyst that includes all schemata, rather than a corpus analysis focusing on an individual pattern (cf. Gjerdingen, 1988; Byros, 2009; Mitchell, 2016; Aerts, 2017). The corpus in Rabinovitch (2015) represents my methodological biases and is therefore not useful here. Gjerdingen's (2007) sample has allowed him to examine the first-order transitional probabilities between schemata (Gjerdingen, 2007, p. 372, Figure 27.1). My analysis of Gjerdingen's annotated corpus provides tentative results regarding the central role of rare intervals in the abstracted skeletons. By detecting common skeletal patterns of the style, Gjerdingen de facto marks certain surface events as salient, which amounts to a form of pitch reduction (Rabinovitch 2019). Despite proposals for formalizing schema or pattern detection (Symons, 2017; Sears, 2017; Finkensiep, Neuwirth, \& Rohrmeier, 2018), schemata are not yet observable features of the musical surface, making this expert-annotated corpus valuable at the present stage.

Gjerdingen proposes galant schemata as a reconstruction of musical communication between expert musicians and enculturated listeners around 1720-1780. Gjerdingen (1988) situates the peak of one particular schema, the ${ }^{\wedge}-^{\wedge} 7 \ldots \wedge 4-^{\wedge} 3$ in the 1770 s based on a corpus study and estimates that schemata in general peaked around 1765 (Gjerdingen, 2007). Byros's (2009) corpus shows that an additional schema peaked in the 1790s. Gjerdingen eschews "macrotheoretical" and "macrohistorical" generalizations and is interested in providing rich, descriptive "microhistories" and "microtheories" of individual patterns. Yet the proximity in time between the peak of the ${ }^{\wedge} 1-\wedge 7 \ldots \wedge 4-\wedge 3$ in the 1770 s and the estimated peak of schemata in general around 1765 based on his career-long study of the style seems to suggest, prima facie, that Gjerdingen's research captures general stylistic trends that peaked somewhere in the latter half of the eighteenth century. Like Gjerdingen's skeletal schemata, the major mode peaked somewhere during the latter half of the eighteenthcentury in terms of the proportion of pieces composed in it. The major mode has a single tritone between ${ }^{\wedge} 4-$ $\wedge 7$, as opposed to the (harmonic) minor mode, which additionally has a prominent ${ }^{\wedge} 2-\wedge 6 \mathrm{~b}$ tritone that creates some tonal ambiguity. (The presence of the ${ }^{\wedge} 2-^{\wedge} 6 b$ tritone in minor may explain the frequent modulations to the relative major in minor-mode pieces.) Schema types over-emphasize tritone resolutions in the outer voices (Rabinovitch, 2018), and their tacit, time-span-reduction-like analytical process (Lerdahl \& Jackendoff, 1983) implies high priority for tritone resolutions within metric segments (Rabinovitch, 2019). Since schemata are closely related to outer-voice tritone resolutions, and since the major mode has a unique tritone (Browne, 1981), the musical "ecosystem" of the latter half of the eighteenth century seems particularly favorable to the abstraction of tritone resolutions as salient outer-voice skeletal events. Abstracting outervoice tritones also reveals the localized key context on which the scale-degree identities of the schemata redundantly rely. Needless to say, the coincidence between the peak of schemata and the peak of the major mode does not imply causation, but only allows us to reflect on some aspects of the style and of the evolving tonal system.

I have referred to the "peak" of the major mode in the latter half of the eighteenth century. This means that major-mode pieces are particularly prevalent proportionally during this half century. This trend is more marked in the latter half of the eighteenth century in comparison with the rest of the common practice narrowly defined (1700-1899), as discussed in musicological and empirical literature to be cited below. In fact, throughout this article I will focus exclusively on the prevalent major mode and will largely ignore the minor mode. Hence, all of my statements about schemata below should have the caveat "when embedded in the major mode..." in front of them, not only since the "ecosystem" of the major mode seems ideally suited for the properties of galant schemata, but also due to its sheer prevalence during the period 1750-1799.

My hypothesis is the following:

H1: The usage of the schemata prioritizes skeletal tritones as vertical intervals at the expense of their diatonic generic counterparts, P5 and P4. Thus, by emphasizing a rare harmonic interval of the diatonic-set template (Browne, 1981) through musical usage as a skeletal interval, the schemata create clarity of local key context. By abstracting characteristic skeletal patterns of the style out of the musical surface, Gjerdingen's analytical process also clarifies localized tonal contexts. I had initially hypothesized that skeletal schemata skew the balance in favor of rare soprano melodic 
semitones as compared to common whole tones, but this is more problematic to evaluate even in the context of the current, preliminary pilot (see below).

Elsewhere, I have showed that Gjerdingen's implicit reductive decisions move from the musical surface to a skeleton by giving priority to tritone-resolutions (or resolution of local ${ }^{\wedge} 4$ over $^{\wedge} 5$ ) within a metric segment implied by his annotations, and otherwise prioritizing the first available vertical consonance within the segment: this heuristic, which amounts to a type of time-span reduction (after Lerdahl \& Jackendoff, 1983), approximates Gjerdingen's analytical choices of skeletal soprano tones within a segment at about $85 \%$ (Rabinovitch 2019). The possibility of reconstructing an aspect of schema reduction according to this heuristic suggests exploring the role of tritone resolutions within schemata from additional angles, as I attempt to do here. The apparent priority given to tritone finding in the pitch-reductive process brings to mind the hypothesis that the rare intervals of the diatonic set are crucial for key finding (Browne, 1981; Butler, 1989; Butler \& Brown, 1994). If schema finding is intertwined with high priority for tritone finding, the processes of pitch reduction and the discovery of the local key context of the schema seem intertwined. Since schemata as typical scale-degree structures rely on a local key-context for their definition, there seems to be some redundancy built into the abstraction of salient pitches and localized key contexts. I recognize, of course, that the rare-interval hypothesis had been seriously questioned if not altogether rejected in favor of distributional models (Krumhansl, 1990). However, we should bear in mind that the improved success of key-finding algorithms (e.g., Albrecht \& Shanahan, 2013) does not necessarily represent the psychology of key finding, which is still an open question (e.g., Temperley \& Marvin, 2008; VanHandel \& Callahan, 2012; Farbood, Marcus, \& Poeppel, 2013; Anta, 2015). Indeed, some of these experiments suggest that scale-degree frequencies by themselves are not sufficient tonal cues for listeners. The current inquiry, of course, cannot give us any information about the minds of listeners, dead or alive. Rather, it is a preliminary exploration of schemata and what they might tell us about the evolving usage of tonally unambiguous tritones within common-practice tonal music. The connection between Meyer and Gjerdingen's ${ }^{\wedge} 1-^{\wedge} 7 \ldots{ }^{\wedge} 4-\wedge 3$ schema (later renamed Meyer) and rare intervals was briefly suggested by Spitzer (2004). The tritone-resolution subschema in several schemata and its key-defining aspect is discussed by Jan $(2013,2015)$ and in more detail in Rabinovitch (2018). The idea that the diatonic ${ }^{\wedge} 4-^{\wedge} 7$ tritone is central in tonality and its evolution is, of course, an old one (Fétis, 1840, 1844), but the changing usage of the interval within a subset of the common practice still requires some exploration: the peak of the schemata in the latter half of the eighteenth century may reveal something about a basic, evolving tonal feature.

What exactly does it mean that an interval is "rare"? The interval vector of the diatonic set is $<254361>$ (Browne, 1981), which creates two pairs of "rare" and "common" intervals with the same generic size: six P5+P4 (ic5) vs. one tritone (ic6), and five whole tones (or minor sevenths, ic2) vs. two semitones (or major sevenths, ic1). In both cases, the "common" interval (P5+P4, whole tone) is tonally ambiguous, while the "rare" one (semitone, tritone) is unambiguous, at least in the context of a tritone resolution without enharmonic reinterpretation, which is generally what is relevant for eighteenth-century music. I had initially hypothesized that skeletal galant schemata skew the balance in favor of the "rare" intervals of the template in both cases: tritones are made more common — or at least are overemphasized —in respect to perfect fifths or fourths as vertical skeletal intervals between the outer voices; semitones are overemphasized at the expense of the common whole tones as melodic motions in the skeletal soprano. The former hypothesis seems to be reflected in the small corpus of complete-movement analyses in Music in the Galant Style (Gjerdingen, 2007); the latter is problematic. The question of common vs. rare intervals is intertwined with a distinction between two types of "rarity":

1) Rarity in the diatonic-set template, to which I will refer below as "rarity in template."

2) Rarity in musical usage in a musical corpus, to which I will refer below as "rarity in usage."

Skeletal tones are the "core tones" of Gjerdingen's (2007) schemata: though Gjerdingen has been averse to contrapuntal reduction of any type, his analytical annotations de facto create pitch reductions (Rabinovitch, 2019). When thinking about musical usage, we have to distinguish between two things:

A) The usage of intervals on the musical surface (surface textures such as those from which Gjerdingen's skeletons are derived);

B) The usage of intervals in the skeletons - melodic intervals in the soprano skeleton and vertical intervals respective to the skeletal bass. 
The distinctions above raise a question regarding the relations between the diatonic-set template, surface usage, and skeletal usage. To my knowledge, this question has been somewhat downplayed in the polemics on rare intervals. The proponents of the rare-interval hypothesis were interested both in the rare intervals of the diatonic template and in the temporal ordering of these elements that eliminates ambiguity (as in a tritone resolution) or, conversely, increases it (Butler, 1989). However, the actual rarity of rare intervals in musical usage seems to me to have been somewhat neglected in those old polemics on key finding. One might ask:

- Are the rare intervals of the diatonic template actually rare in musical usage? Is the ratio in the template between $\mathrm{M} 2$ and $\mathrm{m} 2$ or $\mathrm{P} 5+\mathrm{P} 4$ vs. tritone retained in musical usage, or is it skewed in musical usage in either direction? Are rare-in-template intervals made more or less rare in usage respective to the abstract diatonic template?

In the context of galant schemata, another pertinent question arises:

- What is the relation between surface musical usage and schematic skeletons? Is the abstraction of an outer-voice contrapuntal skeletons associated with a high frequency of tritone resolutions, which makes local key contexts unambiguous?

The ratios in the abstract diatonic-set template are 2.5 for whole-tones vs. semitones (or, more precisely, ic2/ic1, which may also represent major sevenths and minor sevenths), and 6 for perfect fifths and fourths (P5+P4) vs. tritones (after Browne, 1981). Of course, the interval vector of the diatonic set represents not intervals per se, but rather interval classes. For the skeletal vertical (soprano-bass) intervals that are central in my discussion (P5+P4 vs. tritone spelled as aug. 4 or dim. 5), this makes less difference, since tritones are either generic fifths (diminished) or fourths (augmented): the pair of ics that compete are ic6 (tritone, i.e., aug. 4 or dim. 5) and ic5 (P5+P4). For melodic whole and half steps, there are several potential mitigating factors for the fact that ic1 and ic2 encompass both seconds and sevenths:

1) The cyclical, octave-neutral nature of scale degrees, which are the entities captured by Gjerdingen's scale-degree annotations.

2) The rarity of large intervals such as sevenths as melodic intervals, which is cross cultural, a statistical universal if not a universal (Huron, 2006; Savage, Brown, Sakai, \& Currie, 2015).

3) The fact that skeletal scale-degree transitions in galant schemata tend to be stepwise, somewhat similar to Schenker's notion of melodic fluency (Pastille, 1990; Metz, 2017).

Huron's (2008) corpus analysis of the two-part inventions by J. S. Bach-while stemming from different theoretical motivations - allows us to calculate the (P5+P4)/tritone ratio in usage within a 2-voice eighteenth-century corpus as 3.42. Thus, in a 2-voice corpus from the early eighteenth century, the surface usage of tritones makes them proportionally less rare than their share in the abstract diatonic template, yet they are still 3.42 times less likely to occur as surface vertical intervals than their diatonic counterparts, P5 and P4. Of course, it would be preferable to calculate the surface vertical intervals of the corpus of pieces analyzed in Gjerdingen (2007), which would be a way to strengthen the current pilot. In the meantime, Huron's (2008) data give us an approximation from a corpus that is close in time and has the advantage of being a pure 2-voice corpus. If expert analyses into Gjerdingen's schemata by the main proponent of this theoretical position tentatively suggest a further skew in favor of the tritone, it would seem that this abstraction of salient skeletal events coincides with greater clarity of localized key contexts.

It is less clear how to compare frequencies of whole tones and semitones. David Temperley (personal communication, 2017) indicates that the whole-tone/semitone ratio (henceforth: WT/ST ratio) in the first violin parts in the corpus of Haydn and Mozart's string quartets is ca. 1.08, in comparison with the WT/ST ratio of 2.5 of the diatonic template. In other words, whole tones and semitones are almost balanced in their usage. Eighteenth-century music has many chromatic embellishments. The task of manually recording every melodic surface interval in the principal, surface soprano melody of eight of the pieces analyzed in Gjerdingen (2007) or excerpts thereof had proved unwieldy. However, it suggested a WT/ST ratio of 1.34 as a pilot approximation across the intervals recorded - certainly closer to the Haydn and Mozart corpus data than to the diatonic template.

Finding an equal ground for comparison is indeed problematic: Gjerdingen's skeletal schemata rely on a hyper-local sense of key, in which every brief tonicization changes the contextual scale-degree identities of the skeletal events involved, as we have seen above in the discussion of Example 1. The scale degrees 
available in soprano skeletons (Gjerdingen, 2007) are the diatonic scale degrees and one step in the sharp and

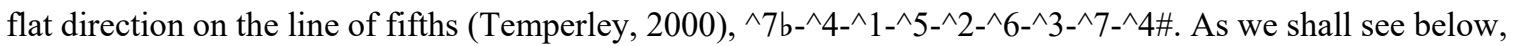
$\wedge 4 \#$ and $\wedge 7 b$ are infrequent in Gjerdingen's annotations. Comparing galant skeletons to Temperley’s Haydn and Mozart calculation is problematic: the principal semitones in skeletal galant usage are local ${ }^{\wedge} 7-\wedge 1$ and $\wedge 4$-^3, whereas the Haydn and Mozart corpus involves chromatic motions, with a larger repertoire of semitones available.

Another possible corpus for comparison is the Essen Folksong Collection (Huron, 2006). Though this is a corpus of European folk melodies, not "art" music, it has some advantages in speculating about the relations between the diatonic template and the usage of "rare" intervals in some variety of Western tonal music. In this corpus, the musical usage is overwhelmingly major, strongly tending towards major-diatonic usage. For instance, by comparing the ratios of mode-dependent transitions, we can see that minor-mode usage is negligible. For instance, the ${ }^{\wedge} 4-^{\wedge} 3$ to ${ }^{\wedge} 4-^{\wedge} 3$ b ratio is ca. 49.13 ; the ${ }^{\wedge} 6-^{\wedge} 5$ to ${ }^{\wedge} 6 b^{\wedge}{ }^{\wedge} 5$ ratio is ca. 173.42 . While the corpus does contain some chromaticism, it is largely major-diatonic. The WT/ST ratio for diatonic-

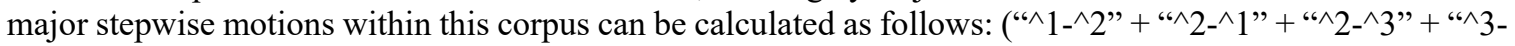

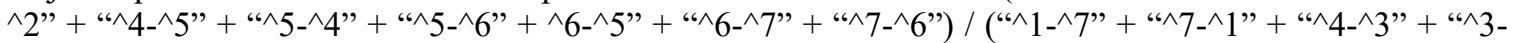
$\left.\wedge^{\prime \prime}\right)=(0.02806+0.04190+0.03282+0.04865+0.01712+0.03653+0.02076+0.03642+0.00854+$ $0.01327) /(0.02321+0.02025+0.04127+0.02644)=2.55527 \approx 2.5$. Thus, if we isolate the major-diatonic stepwise transitions from the Essen corpus, the WT/ST ratio in usage remains almost balanced respective to the ratio in the diatonic-set template, despite the fact that the transitions $\wedge^{\wedge} 6-^{\wedge} 7$ and ${ }^{\wedge} 7-\wedge 6$ are particularly infrequent. In other words, there exists a tonal corpus in which the abstract rarity of semitones in the diatonic collection is nearly mirrored in musical usage.

If we were to add the two chromatic scale degrees that are available in Gjerdingen's skeletal soprano scale-degrees, hence, add $\wedge^{\wedge} 4 \#-\wedge 5, \wedge 5-^{\wedge} 4 \#, \wedge 7 b-\wedge 6, \wedge 6-\wedge 7 b$ from the Essen data to the denominator, the WT/ST ratio would be 2.41. The question of the WT/ST ratio seems even more problematic than that of the (P5+P4)/tritone ratio, and the results in Gjerdingen's analyses are not favorable to my initial hypothesis that skeletal usage overemphasizes semitones. As we shall see, however, the results below indicate that skeletal melodic semitones are very frequently annotated as the locally-diatonic ${ }^{\wedge} 3-\wedge 4$ and ${ }^{\wedge} 4-^{\wedge} 3$ as well as ${ }^{\wedge} 7-\wedge 1$ and $\wedge^{\wedge} 1 \wedge^{\wedge} 7$, highlighting again the affinity between schema finding and the detection of a localized tonal center.

I have cited above the peak of schemata somewhere in the latter half of the eighteenth century (Gjerdingen, 1988, 2007; Byros, 2009). Musicologists have observed the gradual shift from a relatively balanced distribution of major- and minor-mode compositions at the beginning of the eighteenth century to a sheer prevalence of major-mode pieces in its latter half (Riley, 2014). The prevalence of major-mode pieces in this half century respective to the nineteenth century is also clearly reflected in Horn and Huron's (2015) corpus. The latter half of the eighteenth century is thus the relative peak of usage of major-mode compositions within common-practice tonality narrowly defined, 1700-1899. A very rough sketch of the modal history of Western music might be useful here (cf. Lester, 1989; Albrecht \& Huron, 2014; Tompkins, 2017):

1) From modes to a major-minor system (up to 1700 or before);

2) Major and minor modes are relatively equally prevalent (ca. 1700-1749);

3) Major mode as the predominant mode, taking a particularly large share of compositions (ca. 17501799);

4) A relative rise in the usage of the minor mode, 1800-1899.

Horn and Huron's (2015) data for 1750-1899 and Albrecht and Huron's (2014) data for 1700-1749 reflect the sharp fluctuations in the usage of the major and minor modes, as represented in Table 1 by the ratio of major-mode pieces to minor-mode pieces for each half century:

Table 1. Ratio of major-mode/minor-mode compositions through the common-practice era (calculated after Albrecht \& Huron, 2014; Horn \& Huron, 2015)

\begin{tabular}{cc}
\hline Time period & $\begin{array}{c}\text { Ratio of major mode/ } \\
\text { minor mode }\end{array}$ \\
\hline $1700-1749$ & 1.27 \\
$1750-1799$ & 4.88 \\
$1800-1849$ & 2.33 \\
$1850-1899$ & 1.77 \\
\hline
\end{tabular}


Albrecht, Horn, and Huron situate each composer's work in the decade in which the composer turned 25; hence, their results do not reflect work chronology per se. However, their data reflect clear generational trends that mark the latter half of the eighteenth century as the heyday of the major mode. The first half of the eighteenth-century has a fairly balanced distribution of major- and minor-mode pieces, followed by a rise in prevalence of the major mode. After its heyday, the major mode significantly declined throughout the nineteenth century. Though the minor mode did not subsequently overthrow the major mode from its "lead" (nor did it even regain the relative balance of 1700-1749), its share grew in the nineteenth century, especially in its latter half.[3]

When the majority of pieces are cast in the major mode, it is likely to serve as a prototype for both modes. Parncutt (2012, p. 121) writes: "Because major was more common, minor was perceived as a variant of it, rather than the reverse: minor became 'the Other' of the major-minor system." This "otherness" is, of course, particularly relevant surrounding the peak in prevalence of the major mode. One is reminded of Tversky's (1977) classic discussion of the asymmetry in perceived similarity: instead of Tversky's cold-war example of Cuba and the U.S.S.R one might suggest to millennial students that Academia.edu is more similar to Facebook than Facebook is similar to Academia.edu. In the present context, the minor more is more similar to the major mode than the other way around. The roughly joint peak of galant schemata and the major mode allows us to examine the properties of galant schemata when they are embedded in a major-mode context as a central stylistic tendency in the latter half of the eighteenth century.

If one were to imagine a favorable musical ecosystem in which tritone resolutions are associated with skeleton abstraction (Rabinovitch, 2019) and with identifying the hyper-local key context on which the schemata's scale-degree identities rely, then a musical reality dominated by the major mode, with its single tritone, seems ideal and clearest. As stated, the minor mode has two prominent tritones, between ${ }^{\wedge} 7$ and ${ }^{\wedge} 4$ as well as between $\wedge 2$ and $\wedge^{\wedge} 6 \mathrm{~b}$. Again, the joint peaks of the major mode and the schemata do not suggest causality, but rather tell us something about the history of a tonal feature. Gjerdingen (2007, pp. 16-19) proposes the schemata as "cognitive archaeology" or a reconstruction of historical musical communication. The rare-interval hypothesis was a proposal for a cognitive mechanism for key finding in living listeners. Without making direct claims about musical minds, dead or alive, it seems that this joint peak may tell us something about the evolution of the tonal system and the prevalence and salience of tritone resolutions, which opens avenues for future inquiry to be discussed in the conclusion section.

Before I turn to analyzing Gjerdingen's annotations, I would like to take a quick look at the skeletal melodic aspect of Gjerdingen's schemata. The skeletal soprano lines of galant schemata from Gjerdingen (2007) are represented in Diagrams 1a and 1b (see Appendix D) alongside additions by other scholars: Byros (2009, "le-sol-fi-sol"), Rice (2014, "Heartz," 2015, "Morte"), Mitchell (2016, "Volta"), and Aerts (2017, "Svago," similar to Mitchell's Volta but proposed independently). Looking at the list of prototypes may be somewhat similar to looking at the diatonic-set template: without information about usage, it is difficult to assess what this means. However, this representation shows that the diatonic semitones, ${ }^{\wedge} 4{ }^{\wedge} 3$ and ${ }^{\wedge} 1-^{\wedge} 7$, emerge as central junctures of melodic activity, ending many of the patterns. By annotating the musical surface and segmenting it into typical patterns of the style, Gjerdingen highlights patterns ending on a diatonic semitone respective to a highly localized key center.

\section{A PRELIMINARY ASSESSMENT OF GALANT SKELETAL USAGE}

This section offers pilot analyses of skeletal vertical intervals and skeletal melodic intervals in Gjerdingen's analytical annotations. I have included in this survey the full-movement analyses in the following fourteen chapters in Gjerdingen (2007): 5, 8, 10, 12, 15, 17, 19, 21, 22, 23, 24, 26, 28, 29, with pieces by Giovanni Battista Somis, Carl Ditters von Dittersdorf (*2), Joseph Haydn, Christoph Willibald Gluck, Baldassare Galuppi (*2), Johann Christian Bach, Simon Leduc, Leonardo Leo, Niccolò Jommelli, Wolfgang Amadeus Mozart, Johann Joachim Quantz, and Francesco Galeazzi. All fourteen pieces are in the major mode. In the case of an aria da capo, the repetition of the big A section (not re-notated) was not taken into account (only events in the notated portions were recorded). From the Theme and Variations by Haydn (Chapter 10), only the theme was represented, since including all of the variations would have inflated the proportion of tritones and given my hypothesis an unfair advantage. Due to the very small size of the corpus and some of the constituent pieces, and due to the corpus's stylistic uniformity, I have decided to tally skeletal intervals across the entire corpus. The Haydn quartet movement analyzed in the theoretically central Chapter 27, "Il Filo", has been left out of the present survey due to sketch-study issues (Rohringer, 2015). 
Unfortunately for present purposes, the analytical annotations in Gjerdingen (2007) do not provide an exhaustive two-voice skeleton for each movement in its entirety: Gjerdingen does not abstract a skeleton from each and every measure of the music, though he annotates almost all of the musical surface. In analyzing the vertical intervals, I had to devise a method that would create some transparency and allow others to critique my reading of Gjerdingen's annotations, listed in Appendix A (comparing Appendix A to Gjerdingen's annotations would show interested readers that my interpretative freedom was indeed limited). I have used the following principles in analyzing Gjerdingen's annotations:

1) Only explicitly marked soprano (or principal melodic line) skeletal scale-degrees were recorded. If the bass was not marked, it was reconstructed by me based on the score. If the soprano was sustained or immediately re-articulated, the soprano was counted again against a new bass when this was deemed meaningful.

2) If the same interval was implied again by the markings, it was counted again (e.g., C5 over C3 repeated twice in Gjerdingen's annotations). This stems from the assumption that the re-annotation implies markedness of this musical event for Gjerdingen as an analyst and listener.

3) Small-circle markings, typically associated with auxiliary features such as the high-^ 2 and high-^ 6 drop, were not included in the survey. However, when features such as high-^ 2 and high-^ 6 drops were marked with a normal-sized circle, they were recorded in Appendix A.

4) The Cudworth surface elaboration, $\wedge^{\wedge}-\wedge{ }^{\wedge}-^{\wedge} 5-\wedge 4$, annotated inconsistently by Gjerdingen, was taken as $\wedge^{\wedge}$ only, followed by a ${ }^{\wedge}-^{\wedge} 2-\wedge 1$ cadential string, (see Rabinovitch, 2018, 2019), regardless of which of the markings for $\wedge^{\wedge}, \wedge{ }^{\wedge}, \wedge 5$, were present.

The listing of intervals is provided in Appendix A: the ratio of perfect fifths and fourths to tritones (P5+P5)/tritone in it is 1.82 (213 vs. 117 occurrences). This is considerably lower than the surface ratio in Bach's 2-part inventions (after Huron 2008), which is stylistically close. By abstracting a skeleton from the musical surface, Gjerdingen seems to be overemphasizing tonally unambiguous cues. While the tritone is not "ubiquitous," it seems to be prioritized above its "share" in the template and usage in a stylistically proximate corpus. Once again, a calculation of surface soprano-bass intervals in the pieces analyzed by Gjerdingen proper would improve the current, preliminary results.

I have discussed above the problems with comparing surface and skeletal whole tones and semitones, as well as a preliminary survey of eight pieces from Gjerdingen (2007), which suggested a 1.34 surface soprano WT/ST ratio as an approximation, as well as Temperley's data for a related corpus, which indicates $1.08 \mathrm{WT} / \mathrm{ST}$ surface ratio. In order to examine the properties of skeletal melodies in a preliminary fashion, I recorded the soprano scale-degree transitions in the same corpus of 14 analyses from Gjerdingen (2007), shown in Appendix B. The following method has been taken:

1) Only record normal-sized soprano circle annotations;

2) If there is a tonal skip (shift in scale-degree identities due to change of tonal center of reference), leave a space between strings that will not figure in transition counts. If there is an (intuitive) disjunction in the annotation between schemata or groups of schemata, leave a blank space that will not figure in transition counts.

3) Differentiate major-diatonic and minor 6, 3, 7, (vs. 6b, 3b, 7b) as well as 4 and 4\#, so that the chromatic identity of scale degrees is reflected clearly. (Thus, a context like Example 1 would be taken as 4-3b then 4-3).

4) Ignore immediate repetitions of the same scale degree, unless it is reinterpreted in a new tonal segment, in which case it will be represented twice: once at the end of a segment within one key and then once at the beginning of a segment in a different key after a blank space.

5) Same amendment discussed above (under bullet point 4 in the previous list) for the Cudworth;

6) Quiescenza schema taken to be a combination of tritone resolutions (this affected Leduc's piece only, where a soprano line can be reconstructed for the Quiescenza when it is missing, cf. Rabinovitch, 2018, 2019).

Thus, the resultant representation of Appendix B contains scale-degree segments of varying lengths, which are segmented by tonal shifts (on a local level) or what was intuitively interpreted as gaps in the annotation. They give us an assessment of scale-degree frequencies in the annotation as well as a tentative and preliminary sense of scale-degree transitions within individual schemata or within successions of several 
adjacent schemata. (Again, interested readers are welcome to scrutinize the scale-degree successions listed in Appendix B and observe that my interpretative freedom was limited, despite the intuitive decisions on points of disjunction, in which I segmented melodic events into separate strings).

The frequencies of individual skeletal scale degrees are unusual (see Table 2), inter alia since they emphasize $\wedge^{\wedge} 4$ and suppress skeletal $\wedge^{\wedge}$ in comparison with surface properties of melodies (cf. Huron 2006, especially pp. 147-153), though we should keep in mind that these are scale-degree identities respective to a highly localized tonal center. Note the relative rarity of ${ }^{\wedge} 4 \#$ and $\wedge^{\wedge} 7 \mathrm{~b}$, which suggests that Gjerdingen generally interprets skeletal semitones as locally diatonic.

Table 2. Frequency of individual skeletal scale degrees as reflected in the analysis of Appendix B.

\begin{tabular}{|l|l|l|l|l|l|l|l|l|l|l|l|}
\hline Skeletal scale degree & $\wedge 1$ & $\wedge 2$ & $3 b$ & $\wedge 3$ & $\wedge 4$ & $\wedge 4 \#$ & $\wedge 5$ & $6 \mathrm{~b}$ & $\wedge 6$ & $\wedge 7 \mathrm{~b}$ & $\wedge 7$ \\
\hline Frequency & 225 & 136 & 38 & 239 & 236 & 6 & 183 & 19 & 138 & 10 & 109 \\
\hline
\end{tabular}

The frequencies of stepwise transitions within the annotations, represented in Table 3A and Table $3 \mathrm{~B}$, have interesting properties as well:

Table 3A. Frequencies of whole-tone skeletal transitions according to the analysis of Appendix B.

\begin{tabular}{|c|c|}
\hline Scale-degree transitions & Frequency \\
\hline$\wedge^{\wedge} 1-\wedge 2$ & 10 \\
\hline$\wedge^{\wedge}-\wedge 1$ & 67 \\
\hline$\wedge 2-\wedge 3$ & 17 \\
\hline$\wedge 3-\wedge 2$ & 98 \\
\hline$\wedge 3-\wedge 4 \#$ & 2 \\
\hline$\wedge 4-\wedge 5$ & 2 \\
\hline$\wedge 5-\wedge 4$ & 115 \\
\hline$\wedge 5-\wedge 6$ & 14 \\
\hline$\wedge^{\wedge} 6-\wedge 5$ & 89 \\
\hline$\wedge^{\wedge} 6-\wedge 7$ & 19 \\
\hline$\wedge 7-\wedge 6$ & 7 \\
\hline$\wedge 1-^{\wedge} 7 b$ & 10 \\
\hline$\wedge 3 b-\wedge 4$ & 2 \\
\hline$\wedge 4-\wedge 3 b$ & 31 \\
\hline Total & 483 \\
\hline
\end{tabular}

Table 3B. Frequencies of semitone skeletal transitions according to the analysis of Appendix B.

\begin{tabular}{|c|l|}
\hline Scale-degree transitions & Frequency \\
\hline$\wedge 1-^{\wedge} 7$ & 70 \\
\hline$\wedge 7-\wedge 1$ & 52 \\
\hline$\wedge 3-\wedge 4$ & 11 \\
\hline$\wedge 4-\wedge 3$ & 174 \\
\hline$\wedge 3 b-\wedge 2$ & 6 \\
\hline$\wedge 2-\wedge 3 b$ & 3 \\
\hline$\wedge 4 \#-\wedge 5$ & 2 \\
\hline$\wedge 5-\wedge 4 \#$ & 2 \\
\hline$\wedge 4 \#-\wedge 4$ & 4 \\
\hline$\wedge 6 b-\wedge 5$ & 13 \\
\hline$\wedge 5-\wedge 6 b$ & 4 \\
\hline$\wedge 7 b-\wedge 6$ & 10 \\
\hline Total & $\mathbf{3 5 1}$ \\
\hline
\end{tabular}


The WT/ST ratio in this analysis is 1.376 , which does not seem to support a special status for semitones in the abstracted skeleton. However, the major-diatonic semitone transitions, $\wedge 4-^{\wedge} 3$ and $\wedge 3-\wedge 4$ or $\wedge^{\wedge} 7 \wedge^{\wedge} 1$ and $\wedge^{\wedge} 1-^{\wedge} 7$, account for $87.46 \%$ of skeletal semitone transitions in the annotations. Notice, also, that ${ }^{\wedge} 4-$ $\wedge 3$ is the single most common stepwise transition in the annotations. Again, Gjerdingen's analytical process involves both marking salient events as part of typical schemata as well as finding a local key context, which may be intertwined.

The limitations of the present pilot are obvious: Gjerdingen does not annotate the complete musical surface of all 14 pieces within this small corpus, the analysis of the annotations left some limited room for intuitive judgment calls rather than an entirely consistent procedure, and events were tallied across a small corpus with pieces of uneven length. Moreover, it would have been preferable to compare the results of skeletal annotations to the musical surface of the pieces analyzed themselves, rather than to other eighteenthcentury musical corpora serving as proxies. Nevertheless, these preliminary results seem to support the notion that Gjerdingen's abstraction of a contrapuntal skeleton provides considerable emphasis to rare intervals - in particular vertical tritones.

\section{CONCLUSION AND HYPOTHESES FOR FUTURE TESTING}

This article has tentatively suggested possible connections between Gjerdingen's galant schemata, the rare intervals of the diatonic collection, and the peak of the schemata and the major mode in the latter half of the eighteenth century. Whether or not this is related to the clear, redundant, and delightful communication among stylistic insiders in the eighteenth century (Gjerdingen, 2007) or to key finding in present-day listeners, is of course a question that cannot be answered here. Gjerdingen proposes his schemata based on a close study of historical repertoires and teaching methods as well as on his expertise in theory and cognition. The extent to which schemata are learnable given an idiomatic corpus still requires testing (but see Symons, 2017): if Gjerdingen's reconstruction of patterns of musical communication has some validity, his annotations of conventional patterns represent stylistic trends and salient melodic features of eighteenthcentury music. Might these be a way to operationalize and evaluate such trends through observable features of the musical surface as well, bypassing the expert annotations?

Working through a different lens, White (2014) reports that his Bach, Handel, Telemann, and Vivaldi cluster uses inversion-neutral I-V-I and V-I-V sonorities more frequently than I-V $\mathrm{V}^{7}-\mathrm{I}$ and $\mathrm{V}^{7}-\mathrm{I}^{-} \mathrm{V}^{7}$, while the situation is reversed in his first-Viennese cluster (of Haydn, Mozart, Beethoven, and Schubert). White's results almost certainly indicate a rise in the sheer prevalence of surface tritone resolutions in moving from early- to late-eighteenth-century music. If the period 1750-1799 is in fact unique within commonpractice tonality, the importance of the ${ }^{\wedge} 4{ }^{\wedge} 7$ tritone should manifest itself on the musical surface as well. I would like to propose two hypotheses for future testing:

1) During the period $1750-1799$, tritone resolutions or dominant-tonic resolutions that situate ${ }^{\wedge} 4-\wedge 3$ and $\wedge 7-\wedge 1$ in the outer voices are most common; this tendency is more marked in the period 1750-1799 compared to the rest of the common practice, narrowly defined (1700-1899). This can be assessed by testing the percentage of dominant-tonic resolutions containing these strings in the outer voices in comparison with the other chordal/contrapuntal inversions in each 50-year period.

If this hypothesis is correct, it would suggest an increasing tendency to situate an unambiguous tonal cue in the perceptually salient outer voices. In fact, the specific arrangement of ${ }^{\wedge} 7-\wedge 1$ in the bass and ${ }^{\wedge} 4-\wedge 3$ in the soprano seems paradigmatic in Gjerdingen's schemata (Rabinovitch, 2018, 2019): this is almost equivalent to saying that "V6/5-I" with soprano ${ }^{\wedge} 4$ - $^{\wedge} 3$ is the most prevalent localized dominant-tonic resolution in the period respective to the home key or to a secondary key area. In order to operationalize this hypothesis and test it on a corpus, it would be necessary to perform harmonic analysis respective to a local tonic and find an appropriate way to capture $\mathrm{a}^{\wedge} 4 \mathbf{-}^{\wedge} 3$ soprano succession—either as a contiguous pattern or within a certain window. 
My analysis above suggests that the skeletal melodic transition ${ }^{\wedge} 4{ }^{\wedge} 3$ respective to a local tonic is central in Gjerdingen's annotations. On the musical surface itself, I hypothesize that this would also manifest itself in the following way:

2) During the period 1750-1799, descending soprano scalar flourishes of 8 eighth-notes or sixteenthnotes are most frequently of the type ${ }^{\wedge} 4-^{\wedge} 3-^{\wedge} 2-\wedge 1-\wedge 7-\wedge 6-\wedge 5-\wedge 4$ respective to a local center,or STWT-WT-ST-WT-WT-WT in interval sizes: this rotation is more common than any other rotation of the diatonic set as a surface, stepwise element. These flourishes are most common in the time frame 1750-1799 in comparison with other parts of the common-practice period narrowly defined (i.e., 1700-1899).

The ${ }^{\wedge} 4-^{\wedge} 3-\wedge 2-\wedge 1-\wedge 7-\wedge 6-\wedge 5-\wedge 4-(\wedge 3)$ descending flourish encodes the motion ${ }^{\wedge} 4-^{\wedge} 3$ in a skeletal fashion between two successive strong beats and also - following the flourish - as an adjacency across a metric boundary (cf. Creel, Newport, \& Aslin, 2004; Symons, 2017; Rabinovitch, 2018). If this hypothesis is true, it would further emphasize the importance of skeletal soprano ${ }^{\wedge} 4-^{\wedge} 3$ respective to a local tonic, whose tonal identity would likely be supported by skeletal bass $\wedge^{\wedge} 7-^{\wedge} 1$ (or $\left.{ }^{\wedge} 5-\wedge 1\right)$.

Gjerdingen offers a rich and impressive description of the galant style, based on his expertise in music theory, history, and cognition. He eschews theoretical generalizations and favors "microtheories" and "microhistories" of individual, multi-featured prototypes. While Gjerdingen's rich descriptions of individual patterns have considerable merit and enrich our understanding of eighteenth-century style, his patterns also seem to point to some general stylistic trends. The rise of Gjerdingen's schemata may point to the growing prevalence and salience of "rare" tritone resolutions, which - as controversial as they have been in empirical scholarship - are unambiguous indicators of a local tonal context. Since the peak of the schemata is somewhere in the second half of the eighteenth century, it also coincides with the half-century of tonal music most strongly dominated by the major mode, with its unique tritone. I hope that this article will participate in dialogs about schemata, rare intervals, and tonality among "armchair" scholars like myself and more empirically-minded scholars.

\section{ACKNOWLEDGMENTS}

I am grateful to David Temperley and David Sears for their help with this project. This article was copyedited by Niels Chr. Hansen and layout edited by Diana Kayser.

\section{NOTES}

[1] The title of this article alludes to Perlman's (2004) book, which traces the emergence of theoretical abstractions regarding melodic skeletons in Javenese gamelan musicians' ways of theorizing about their musical tradition. While cross-cultural studies do not yet allow us to assess the relations between skeletons and surface patterns in the musics of the world and the continuum of fixity and flexibility in composition, improvisation, and performance (cf. Jeffery, 1992), the examination of skeletal frameworks like Gjerdingen's might ultimately enrich discussions of melodic skeletons and surface activity in a variety of musical traditions.

[2] Correspondence can be addressed to Gilad Rabinovitch, Florida State University College of Music, grabinovitch@fsu.edu.

[3] The asymmetry between the major and minor modes is also responsible for the "markedness" of meaning associated with the minor mode (Hatten, 1994). Beethoven's works, which are Hatten's focus, are early nineteenth-century pieces that are heard at the backdrop of the spike in prevalence of major-mode pieces. In fact, Beethoven was ideally situated in history to exploit the rarity and markedness of the minor mode: he was active after the peak in prevalence of the major mode, making the minor-mode effect in some of his works particularly stark and fresh. In contrast, for a listener in the 1890s, say, the mere use of the minor mode might already have sounded more normative and trivial. De-automatizing our casual experience of minormode romantic music is thus part of our task if we can ever hope - like Gjerdingen and Byros - to uncover historical modes of listening. 


\section{REFERENCES}

Aerts, H. (2017, June). The svago: methodological reflections on a schema in solfeggi by Leonardo Leo (1694-1744). Paper presented at the $9^{\text {th }}$ EuroMAC Conference, Strasbourg, France.

Albrecht, J. D., \& Huron, D. (2014). A statistical approach to tracing the historical development of major and minor pitch distributions, 1400-1750. Music Perception, 31(3), 223-243. https://doi.org/10.1525/mp.2014.31.3.223

Albrecht, J. D., \& Shanahan, D. (2013). The use of large corpora to train a new type of key-finding algorithm: An improved treatment of the minor mode. Music Perception, 31(1), 59-67. https://doi.org/10.1525/mp.2013.31.1.59

Anta, J. F. (2015). Pitch: a key factor in tonality induction. Music Perception, 32(4), 413-433. https://doi.org/10.1525/mp.2015.32.4.413

Browne, R. (1981). Tonal implications of the diatonic set. In Theory Only, 5(6-7), 3-21.

Butler, D. (1989). Describing the perception of tonality in music: A critique of the tonal hierarchy theory and a proposal for a theory of intervallic rivalry. Music Perception, 6(3), 219-241. https://doi.org/10.2307/40285588

Butler, D. \& Brown, H. (1994). Describing the mental representation of tonality in music. In R. Aiello and J. A. Sloboda (Eds.), Musical perceptions (pp. 193-212). New York, NY: Oxford University Press.

Byros, V. (2009). Foundations of tonality as situated cognition, 1730-1830: an enquiry into the culture and cognition of eighteenth-century tonality with Beethoven's "Eroica" symphony as a case study. Unpublished doctoral dissertation, Yale University, USA.

Creel, S. C., Newport, E. L., \& Aslin, R. N. (2004). Distant melodies: statistical learning of nonadjacent dependencies in tone sequences. Journal of Experimental Psychology: Learning, Memory, and Cognition, 30(5), 1119-1130. https://doi.org/10.1037/0278-7393.30.5.1119

Farbood, M. M., Marcus, G., \& Poeppel, D. (2013). Temporal dynamics and the identification of musical key. Journal of Experimental Psychology: Human Perception and Performance, 39(4), 911-918. https://doi.org/10.1037/a0031087

Fétis, F.-J. (1840). Esquisse de l'histoire de l'harmonie, considérée comme art et comme science systématique. Paris, France: Bourgogne \& Martinet.

Fétis, F.-J. (1844). Traité complet de la théorie et de la pratique de l'harmonie. Paris, France: Schlesinger.

Finkensiep, C., Neuwirth, M., \& Rohrmeier, M. (2018). Generalized Skipgrams for Pattern Discovery in Polyphonic Streams. In Proceedings of the $19^{\text {th }}$ International Society for Music Information Retrieval Conference (pp. 547-553). Paris, France.

Gjerdingen, R. O. (1988). A classic turn of phrase: music and the psychology of convention. Philadelphia, PA: University of Pennsylvania Press.

Gjerdingen, R. O. (2007). Music in the galant style. New York, NY: Oxford University Press.

Hatten, R. (1994). Musical meaning in Beethoven: markedness, correlation, and interpretation. Bloomington, IN: Indiana University Press. 
Holtmeier, L. (2011). Funktionale Mehrdeutigkeit, Tonalität und arabische Stufen: Überlegungen zu einer Reform der harmonischen Analyse. Zeitschrift der Gesellschaft für Musiktheorie, 8(3), 465-487. https://doi.org/10.31751/655

Horn, K., \& Huron, D. (2015). On the changing use of the major and minor modes, 1750-1900. Music Theory Online, 21(1). https://doi.org/10.30535/mto.21.1.4

Huron, D. (2006). Sweet anticipation: music and the psychology of expectation. Cambridge, MA: MIT Press. https://doi.org/10.7551/mitpress/6575.001.0001

Huron, D. (2008) Asynchronous preparation of tonally fused intervals in polyphonic music. Empirical Musicology Review, 3(1), 11-21. https://doi.org/10.18061/1811/31695

Jan, S. (2013). Using galant schemata as evidence for universal Darwinism. Interdisciplinary Science Reviews, 38(2), 149-168. https://doi.org/10.1179/0308018813Z.00000000042

Jan, S. (2015). Memetic perspectives on the evolution of tonal systems in music. Interdisciplinary Science Reviews, 40(2), 145-167. https://doi.org/10.1179/0308018815Z.000000000110

Jeffery, P. (1992). Re-envisioning past musical cultures: Ethnomusicology in the study of Gregorian chant. Chicago, IL: University of Chicago Press.

Krumhansl, C. L. (1990). Cognitive foundations of musical pitch. New York, NY: Oxford University Press.

Lerdahl, F. \& Jackendoff, R. (1983). A generative theory of tonal music. Cambridge, MA: MIT Press.

Lester, J. (1989). Between modes and keys: German theory, 1592-1802. Stuyvesant, NY: Pendragon.

Lester, J. (1992) Compositional theory in the eighteenth century. Cambridge, MA: Harvard

University Press.

Metz, A. (2017, June). Melodic fluency in keyboard menuet improvisation. Paper presented at the $9^{\text {th }}$ EuroMAC conference, Strasbourg, France.

Mitchell, N. (2016, April). The Volta: a galant gesture of culmination. Paper presented at the annual meeting of the Music Theory Society of the Mid-Atlantic, Philadelphia, PA.

Parncutt. R. (2012). Major-minor tonality, Schenkerian prolongation, and emotion: a commentary on Huron and Davis (2012). Empirical Musicology Review, 7(3-4), 118-137. https://doi.org/10.18061/emr.v7i3-4.3731

Pastille, W. (1990). The development of the Ursatz in Schenker's published works. In A. Cadwallader (Ed.), Trends in Schenkerian research (pp. 71-85). New York, NY: Schirmer.

Perlman, M. (2004). Unplayed melodies: Javanese gamelan and the genesis of music theory. Berkeley, CA: University of California Press.

Rabinovitch, G. (2015). Tracing galant threads: Gjerdingen's schemata and the evolution of musical form, 1730-1780. Unpublished doctoral dissertation, University of Rochester, USA.

Rabinovitch, G. (2018). Gjerdingen's schemata re-examined. Journal of Music Theory, 62(1), 41-84. https://doi.org/10.1215/00222909-4450636

Rabinovitch, G. (2019). Implicit counterpoint in Gjerdingen's schemata. Music Theory \& Analysis 6(1), 149. https://doi.org/10.11116/MTA.6.1.1 
Rice, J. A. (2014). The Heartz: A galant schema from Corelli to Mozart. Music Theory Spectrum, 36(2), 315332. https://doi.org/10.1093/mts/mtu016

Rice, J. A. (2015). The Morte: a galant voice-leading schema as emblem of lament and compositional building-block. Eighteenth-Century Music, 12(2), 157-181. https://doi.org/10.1017/S1478570615000287

Riley, M. (2014). The Viennese minor-key symphony in the age of Haydn and Mozart. New York, NY: Oxford University Press. https://doi.org/10.1093/acprof:oso/9780199349678.001.0001

Rohringer, S. (2015). Schemata und Systemcharakter. Zeitschrift der Gesellschaft für Musiktheorie, 12(1), 27-68. https://doi.org/10.31751/841

Savage, P. E., Brown, S., Sakai, E., \& Currie, T. E. (2015). Statistical universals reveal the structures and functions of human music. Proceedings of the National Academy of Sciences, 112(29), 8987-8992. https://doi.org/10.1073/pnas.1414495112

Sears, David. (2017, June). Family resemblance and the classical cadence typology: Classification using phylogenetic trees. Paper presented at the $9^{\text {th }}$ EuroMAC conference, Strasbourg, France.

Spitzer, M. (2004). Metaphor and musical thought. Chicago, IL: University of Chicago Press. https://doi.org/10.7208/chicago/9780226279435.001.0001

Symons, J. (2017). A cognitively inspired method for the statistical analysis of eighteenth-century music, as applied in two corpus studies. Unpublished doctoral dissertation, Northwestern University, USA.

Temperley, D. (2000) The line of fifths. Music Analysis, 19(3), 289-319. https://doi.org/10.1111/1468-2249.00122

Temperley, D. \& Marvin, E. W. (2008). Pitch-class distribution and the identification of key. Music Perception, 25(3), 193-212. https://doi.org/10.1525/mp.2008.25.3.193

Tompkins, D. C. (2017). Early seventeenth-century harmonic practice: A corpus study of tonality, modality, and harmonic function in Italian secular song with baroque guitar accompaniment in alfabeto tablature. Unpublished doctoral dissertation, Florida State University, USA.

Tversky, A. (1977). Features of similarity. Psychological Review, 84(4), 327-352. https://doi.org/10.1037/0033-295X.84.4.327

VanHandel, L., \& Callahan, M. (2012). The role of phrase location in key identification by pitch-class distribution. In Cambouropoulos, E., Tsougkras, K., \& Mavromatis, P., \& Pastiadis, K. (Eds.), Proceedings of the $12^{\text {th }}$ International Conference on Music Perception and Cognition and the $8^{\text {th }}$ Triennial Conference of the European Society for the Cognitive Sciences of Music (pp. 1069-1073). Thessaloniki, Greece.

White, C. W. (2014). Changing styles, changing corpora, changing tonal models. Music Perception, 31(3), 244-253. https://doi.org/10.1525/mp.2014.31.3.244 


\section{APPENDIX A: \\ ANALYSIS OF GJERDINGEN (2007), VERTICAL INTERVALS}

Chapter 5 - Somis

\begin{tabular}{|l|l|l|l|}
\hline Measure number & Position (a,b,c...) & Interval & comments \\
\hline 1 & A & P8 & \\
\hline 1 & B & m6 & \\
\hline 2 & A & m3 & \\
\hline 2 & B & m3 & \\
\hline 3 & A & M3 & \\
\hline 3 & B & m3 & \\
\hline 4 & A & m3 & \\
\hline 4 & B & m7 & \\
\hline 4 & C & M3 & \\
\hline 5 & A & M3 & \\
\hline 6 & A & m3 & \\
\hline 7 & A & m3 & \\
\hline 8 & A & M3 & \\
\hline 10 & A & m3 & \\
\hline 12 & A & M3 & \\
\hline 14 & A & M3 & \\
\hline 15 & A & m3 & \\
\hline 16 & A & m3 & \\
\hline 17 & A & M3 & \\
\hline 18 & A & P5 & \\
\hline
\end{tabular}

Chapter 8 - Dittersdorf String Quartet

\begin{tabular}{|l|l|l|l|}
\hline Measure number & Position $(\mathrm{a}, \mathrm{b}, \mathrm{c} \ldots)$ & Interval & Comments \\
\hline 1 & A & P8 & \\
\hline 2 & A & m3 & \\
\hline 3 & A & m3 & \\
\hline 4 & A & M3 & \\
\hline 5 & A & M3 & \\
\hline 5 & B & m3 & \\
\hline 6 & A & m3 & \\
\hline 7 & A & M3 & \\
\hline 9 & A & Dim5 & \\
\hline 10 & A & M3 & \\
\hline 11 & A & Dim5 & \\
\hline 12 & A & M3 & \\
\hline 12 & B & m6 & \\
\hline 13 & A & Aug4 & \\
\hline 13 & B & M3 & \\
\hline 13 & C & M6 & \\
\hline 14 & A & P4 & \\
\hline 14 & B & M3 & \\
\hline
\end{tabular}

Chapter 10 - Haydn variations (theme only)

\begin{tabular}{|l|l|l|l|}
\hline Measure number & Position (a,b,c...) & Interval & Comments \\
\hline 1 & A & m6 & \\
\hline 2 & A & M6 & \\
\hline 3 & A & Dim5 & \\
\hline
\end{tabular}




\begin{tabular}{|l|l|l|l|}
\hline 4 & A & M3 & \\
\hline 5 & A & M3 & \\
\hline 6 & A & m3 & \\
\hline 7 & A & P8 & \\
\hline 10 & A & Dim5 & \\
\hline 10 & B & M3 & chromaticized \\
\hline 12 & A & Dim5 & \\
\hline 12 & B & M3 & \\
\hline 17 & A & m6 & \\
\hline 18 & A & M6 & \\
\hline 19 & A & Dim5 & \\
\hline 20 & A & M3 & \\
\hline 21 & A & M3 & \\
\hline 22 & A & m3 & \\
\hline 23 & A & P8 & \\
\hline
\end{tabular}

Chapter 12 - Gluck

\begin{tabular}{|c|c|c|c|}
\hline Measure number & Position $(\mathrm{a}, \mathrm{b}, \mathrm{c} \ldots)$ & Interval & Comments \\
\hline 1 & A & P8 & \\
\hline 1 & B & $\mathrm{m} 6$ & \\
\hline 2 & A & $\mathrm{m} 3$ & \\
\hline 2 & B & $\mathrm{m} 6$ & \\
\hline 2 & $\mathrm{C}$ & P5 & \\
\hline 2 & $\mathrm{D}$ & M6 & \\
\hline 2 & E & $\mathrm{m} 7$ & \\
\hline 3 & $\mathrm{~A}$ & M3 & \\
\hline 3 & $\mathrm{~B}$ & M3 & \\
\hline 4 & $\mathrm{~A}$ & P5 & \\
\hline 4 & $\mathrm{~B}$ & $\mathrm{~m} 3$ & \\
\hline 5 & $\mathrm{~A}$ & M3 & \\
\hline 6 & $\mathrm{~A}$ & M3 & \\
\hline 6 & $\mathrm{~B}$ & M3 & \\
\hline 6 & $\mathrm{C}$ & P8 & \\
\hline 6 & $\mathrm{D}$ & M3 & \\
\hline 6 & $\mathrm{E}$ & M3 & \\
\hline 7 & $\mathrm{~A}$ & $\mathrm{~m} 3$ & \\
\hline 7 & $\mathrm{~B}$ & $\mathrm{~m} 3$ & \\
\hline 7 & $\mathrm{C}$ & $\mathrm{m} 3$ & \\
\hline 7 & $\mathrm{D}$ & M3 & \\
\hline 7 & $\mathrm{E}$ & M6 & \\
\hline 7 & $\mathrm{~F}$ & P5 & \\
\hline 8 & A & P8 & \\
\hline 8 & $\mathrm{~B}$ & M6 & \\
\hline 8 & C & P5 & \\
\hline 8 & $\mathrm{D}$ & P8 & \\
\hline 9 & $\mathrm{~A}$ & Aug2 & \\
\hline 9 & $\mathrm{~B}$ & M3 & \\
\hline 9 & $\mathrm{C}$ & Aug4 & \\
\hline 9 & $\mathrm{D}$ & M6 & \\
\hline 10 & $\mathrm{~A}$ & Aug2 & \\
\hline 10 & $\mathrm{~B}$ & M3 & \\
\hline 10 & $\mathrm{C}$ & Aug4 & \\
\hline 10 & $\mathrm{D}$ & $\mathrm{m} 6$ & \\
\hline
\end{tabular}




\begin{tabular}{|l|l|l|l|}
\hline 10 & E & P8 & \\
\hline 11 & A & m6 & \\
\hline 11 & B & m6 & \\
\hline 12 & A & M3 & \\
\hline 12 & B & m3 & \\
\hline 13 & A & m3 & \\
\hline 13 & B & M3 & \\
\hline 13 & C & M3 & \\
\hline 13 & D & m3 & \\
\hline 14 & E & m3 & \\
\hline 14 & A & M3 & \\
\hline 14 & B & M3 & \\
\hline 14 & C & m3 & \\
\hline 14 & D & E 3 & \\
\hline 14 & F & M3 & \\
\hline 14 & G & P4 & \\
\hline 15 & A & M3 & \\
\hline 15 & B & P8 & \\
\hline 15 & C & M6 & \\
\hline 15 & D & P5 & \\
\hline 15 & E & P8 & \\
\hline 15 & F & M3 & \\
\hline 15 & G & m3 & \\
\hline 16 & A & m3 & M3 \\
\hline 16 & C & M6 & \\
\hline 16 & D & P5 & \\
\hline 16 & & P8 & \\
\hline
\end{tabular}

Chapter 15 - Galuppi grave sostenuto

\begin{tabular}{|l|l|l|l|}
\hline Measure number & Position (a,b,c...) & Interval & Comments \\
\hline 2 & A & m7 & \\
\hline 2 & B & M6 & \\
\hline 4 & A & P4 & \\
\hline 4 & B & M3 & \\
\hline 5 & A & M3 & \\
\hline 6 & A & m3 & \\
\hline 7 & A & m3 & \\
\hline 8 & A & M3 & \\
\hline 9 & A & m2 & \\
\hline 9 & B & P8 & \\
\hline 9 & C & m7 & \\
\hline 10 & A & m3 & \\
\hline 11 & A & m2 & \\
\hline 11 & B & P8 & \\
\hline 11 & C & m7 & \\
\hline 12 & A & M3 & \\
\hline 13 & A & m7 & \\
\hline 14 & A & m3 & \\
\hline 14 & B & m7 & \\
\hline 15 & A & M3 & \\
\hline 16 & A & m3 & \\
\hline 17 & A & m3 & \\
\hline
\end{tabular}




\begin{tabular}{|c|c|c|c|}
\hline 18 & $\mathrm{~A}$ & M3 & \\
\hline 19 & A & $\mathrm{m} 2$ & \\
\hline 19 & $\mathrm{~B}$ & P8 & \\
\hline 19 & $\mathrm{C}$ & $\mathrm{m} 7$ & \\
\hline 20 & A & $\mathrm{m} 3$ & \\
\hline 21 & A & M2 & \\
\hline 21 & B & P8 & \\
\hline 21 & $\mathrm{C}$ & $\mathrm{m} 7$ & \\
\hline 22 & A & M3 & \\
\hline 24 & A & P5 & \\
\hline 24 & B & M6 & \\
\hline 25 & A & P8 & \\
\hline 26 & A & P8 & \\
\hline 27 & A & P8 & \\
\hline 27 & B & P8 & \\
\hline 27 & $\mathrm{C}$ & P8 & \\
\hline 28 & A & M6 & \\
\hline 28 & B & P5 & \\
\hline 29 & A & P8 & \\
\hline 29 & B & P5 & \\
\hline 29 & C & M6 & \\
\hline 29 & D & M7 & \\
\hline 30 & A & P8 & \\
\hline 30 & B & P5 & \\
\hline 30 & C & M6 & \\
\hline 30 & $\mathrm{D}$ & M7 & \\
\hline 31 & $\mathrm{~A}$ & P8 & \\
\hline 31 & $\mathrm{~B}$ & $\mathrm{~m} 3$ & \\
\hline 31 & $\mathrm{C}$ & M3 & \\
\hline 31 & $\mathrm{D}$ & Aug4 & \\
\hline 32 & A & $\mathrm{m} 6$ & \\
\hline 32 & B & $\mathrm{m} 3$ & \\
\hline 32 & C & M3 & \\
\hline 32 & D & M6 & \\
\hline 33 & A & P8 & \\
\hline 34 & A & $\mathrm{m} 2$ & \\
\hline 34 & B & P8 & \\
\hline 34 & C & $\mathrm{m} 7$ & \\
\hline 35 & A & $\mathrm{m} 3$ & \\
\hline 36 & A & $\mathrm{m} 2$ & \\
\hline 36 & B & P8 & \\
\hline 36 & C & $\mathrm{m} 7$ & \\
\hline 37 & A & M3 & \\
\hline 37 & B & P8 & \\
\hline 37 & C & P8 & \\
\hline 38 & A & P5 & \\
\hline 38 & B & P5 & \\
\hline 39 & A & P8 & \\
\hline 40 & A & M6 & \\
\hline 42 & A & P8 & \\
\hline 42 & B & P8 & \\
\hline 42 & C & $\mathrm{m} 6$ & \\
\hline 42 & $\mathrm{D}$ & P5 & \\
\hline
\end{tabular}




\begin{tabular}{|c|c|c|c|}
\hline 43 & $\mathrm{~A}$ & P8 & \\
\hline 44 & $\mathrm{~A}$ & M6 & \\
\hline 45 & $\mathrm{~A}$ & P8 & \\
\hline 47 & $\mathrm{~A}$ & $\mathrm{~m} 7$ & \\
\hline 47 & $\mathrm{~B}$ & M6 & \\
\hline 49 & $\mathrm{~A}$ & $\mathrm{P} 4$ & \\
\hline 49 & B & M3 & \\
\hline 51 & $\mathrm{~A}$ & $\mathrm{~m} 6$ & \\
\hline 51 & B & P5 & \\
\hline 52 & $\mathrm{~A}$ & M3 & \\
\hline 53 & A & M3 & \\
\hline $\begin{array}{l}54 \\
\end{array}$ & $\mathrm{~A}$ & $\mathrm{~m} 2$ & \\
\hline 54 & $\mathrm{~B}$ & P8 & \\
\hline 54 & $\mathrm{C}$ & $\mathrm{m} 7$ & \\
\hline 55 & $\mathrm{~A}$ & $\mathrm{~m} 3$ & \\
\hline 56 & $\mathrm{~A}$ & $\mathrm{~m} 2$ & \\
\hline 56 & B & P8 & \\
\hline $\begin{array}{l}56 \\
\end{array}$ & $\mathrm{C}$ & $\mathrm{m} 7$ & \\
\hline 57 & A & M3 & \\
\hline 58 & A & $\mathrm{m} 2$ & \\
\hline 58 & B & P8 & \\
\hline 58 & $\mathrm{C}$ & $\mathrm{m} 7$ & \\
\hline 59 & A & $\mathrm{m} 3$ & \\
\hline 60 & $\mathrm{~A}$ & M2 & \\
\hline 60 & B & P8 & \\
\hline 60 & C & $\mathrm{m} 7$ & \\
\hline 61 & A & M3 & \\
\hline 63 & A & P5 & \\
\hline 63 & B & M6 & \\
\hline 64 & A & P8 & \\
\hline 65 & A & P8 & \\
\hline 66 & $\mathrm{~A}$ & P8 & \\
\hline 66 & B & P8 & \\
\hline 66 & C & P8 & \\
\hline 67 & A & M6 & \\
\hline 67 & B & P5 & \\
\hline 68 & A & M3 & \\
\hline 70 & A & M6 & \\
\hline 70 & B & P5 & \\
\hline 71 & $\mathrm{~A}$ & P8 & \\
\hline
\end{tabular}

Chapter 17 - Dittersdorf Quintet

\begin{tabular}{|l|l|l|l|}
\hline Measure number & Position (a,b,c...) & Interval & Comments \\
\hline 1 & A & P8 & \\
\hline 1 & B & P5 & \\
\hline 2 & A & M3 & \\
\hline 3 & A & P8 & \\
\hline 4 & A & P5 & \\
\hline 5 & A & P5 & \\
\hline 6 & A & M3 & \\
\hline 7 & A & P8 & \\
\hline 8 & A & P5 & \\
\hline 9 & A & P5 & \\
\hline
\end{tabular}




\begin{tabular}{|c|c|c|c|}
\hline 10 & $\mathrm{~A}$ & M3 & \\
\hline 11 & A & M3 & \\
\hline 12 & $\mathrm{~A}$ & $\mathrm{~m} 3$ & \\
\hline 13 & $\mathrm{~A}$ & $\mathrm{~m} 3$ & \\
\hline 14 & A & M3 & \\
\hline 14 & B & $\mathrm{m} 6$ & \\
\hline 15 & A & M3 & \\
\hline 15 & B & P8 & \\
\hline 15 & $\mathrm{C}$ & $\mathrm{m} 7$ & \\
\hline 16 & A & P5 & \\
\hline 16 & B & $\mathrm{m} 6$ & \\
\hline 17 & A & M3 & \\
\hline 17 & B & P8 & \\
\hline 18 & A & P8 & \\
\hline 23 & $\mathrm{~A}$ & Dim5 & \\
\hline 24 & A & M3 & \\
\hline 25 & A & $\mathrm{m} 6$ & \\
\hline 25 & B & Dim5 & \\
\hline 26 & A & M3 & \\
\hline 26 & B & P8 & \\
\hline 26 & C & M6 & \\
\hline 27 & A & $\mathrm{m} 6$ & \\
\hline 27 & B & $\mathrm{m} 6$ & \\
\hline 27 & C & Dim5 & \\
\hline 28 & A & M3 & \\
\hline 30 & A & P4 & \\
\hline 30 & B & M3 & \\
\hline 33 & A & P4 & \\
\hline 33 & B & M3 & \\
\hline 34 & A & P8 & \\
\hline 47 & A & P8 & \\
\hline 47 & B & $\mathrm{m} 3$ & \\
\hline 47 & C & $\mathrm{m} 3$ & \\
\hline 47 & D & M3 & \\
\hline 48 & $\mathrm{~A}$ & $\mathrm{~m} 3$ & \\
\hline 48 & B & $\mathrm{m} 3$ & \\
\hline 48 & $\mathrm{C}$ & M3 & \\
\hline 49 & A & $\mathrm{m} 6$ & \\
\hline 50 & $\mathrm{~A}$ & P5 & \\
\hline 51 & A & P4 & \\
\hline 52 & A & M3 & \\
\hline 53 & A & $\mathrm{m} 6$ & \\
\hline 54 & A & P5 & \\
\hline 55 & A & P4 & \\
\hline 56 & A & P5 & \\
\hline 67 & A & $\mathrm{m} 6$ & \\
\hline 68 & A & M3 & \\
\hline 69 & A & $\mathrm{m} 6$ & \\
\hline 70 & A & M3 & \\
\hline 71 & A & $\mathrm{m} 6$ & \\
\hline 72 & A & Aug4 & \\
\hline 73 & A & $\operatorname{Dim} 5$ & \\
\hline 74 & $\mathrm{~A}$ & Aug4 & \\
\hline
\end{tabular}




\begin{tabular}{|c|c|c|c|}
\hline 75 & $\mathrm{~A}$ & Dim5 & \\
\hline 76 & A & P5 & \\
\hline 76 & $\mathrm{~B}$ & $\mathrm{~m} 7$ & \\
\hline 77 & $\mathrm{~A}$ & M2 & \\
\hline 77 & B & $\mathrm{m} 7$ & \\
\hline 78 & $\mathrm{~A}$ & P5 & \\
\hline 78 & B & M3 & \\
\hline 78 & $\mathrm{C}$ & P8 & \\
\hline 79 & $\mathrm{~A}$ & P8 & \\
\hline 79 & B & P5 & \\
\hline 80 & A & M3 & \\
\hline 81 & $\mathrm{~A}$ & P8 & \\
\hline 82 & A & P5 & \\
\hline 83 & A & P5 & \\
\hline 84 & $\mathrm{~A}$ & M3 & \\
\hline 85 & $\mathrm{~A}$ & P8 & \\
\hline 86 & A & P5 & \\
\hline 87 & $\mathrm{~A}$ & P5 & \\
\hline 88 & A & M3 & \\
\hline 89 & A & M3 & \\
\hline 90 & $\mathrm{~A}$ & $\mathrm{~m} 3$ & \\
\hline 91 & $\mathrm{~A}$ & $\mathrm{~m} 3$ & \\
\hline 92 & A & M3 & \\
\hline 92 & $\mathrm{~B}$ & $\mathrm{~m} 6$ & \\
\hline 93 & $\mathrm{~A}$ & M3 & \\
\hline 93 & B & P8 & \\
\hline 93 & C & $\begin{array}{ll}\mathrm{m} 7 \\
\end{array}$ & \\
\hline 94 & $\mathrm{~A}$ & P5 & \\
\hline 94 & B & $\mathrm{m} 6$ & \\
\hline 95 & $\mathrm{~A}$ & M3 & \\
\hline 95 & B & P8 & \\
\hline 96 & $\mathrm{~A}$ & P8 & \\
\hline 96 & B & $\mathrm{m} 6$ & \\
\hline 97 & A & M3 & \\
\hline 97 & B & P8 & \\
\hline 97 & C & m7 & \\
\hline 98 & A & P5 & \\
\hline 98 & B & $\mathrm{m} 6$ & \\
\hline 99 & $\mathrm{~A}$ & M3 & \\
\hline 99 & B & P8 & \\
\hline 100 & $\mathrm{~A}$ & P8 & \\
\hline 105 & $\mathrm{~A}$ & Dim5 & \\
\hline 106 & A & M3 & \\
\hline 106 & B & P8 & \\
\hline 106 & C & M6 & \\
\hline 107 & A & $\mathrm{m} 6$ & \\
\hline 107 & B & $\mathrm{m} 6$ & \\
\hline 107 & C & Dim5 & \\
\hline 108 & A & M3 & \\
\hline 108 & B & P8 & \\
\hline 108 & C & M6 & \\
\hline 109 & A & $\mathrm{m} 6$ & \\
\hline 109 & B & $\mathrm{m} 6$ & \\
\hline
\end{tabular}




\begin{tabular}{|l|l|l|l|}
\hline 109 & C & Dim5 & \\
\hline 110 & A & M3 & \\
\hline 113 & A & M3 & \\
\hline 113 & B & P8 & \\
\hline 113 & C & M6 & \\
\hline 114 & A & m6 & \\
\hline 114 & B & m6 & \\
\hline 114 & C & Dim5 & \\
\hline 115 & A & M3 & \\
\hline 115 & B & P8 & \\
\hline 115 & C & M6 & \\
\hline 116 & A & m6 & \\
\hline 116 & B & m6 & \\
\hline 116 & C & Dim5 & \\
\hline 117 & A & M3 & \\
\hline
\end{tabular}

Chapter 19 - J.C. Bach

\begin{tabular}{|c|c|c|c|}
\hline Measure number & Position $(\mathrm{a}, \mathrm{b}, \mathrm{c} \ldots)$ & Interval & Comments \\
\hline 1 & A & P5 & \\
\hline 1 & B & P8 & \\
\hline 2 & A & $\mathrm{m} 3$ & \\
\hline 2 & $\mathrm{~B}$ & $\mathrm{~m} 7$ & \\
\hline 3 & A & P5 & \\
\hline 3 & $\mathrm{~B}$ & P8 & \\
\hline 4 & A & M6 & \\
\hline 4 & $\mathrm{~B}$ & P5 & \\
\hline 4 & $\mathrm{C}$ & M3 & \\
\hline 5 & A & P8 & \\
\hline 6 & A & M6 & \\
\hline 6 & $\mathrm{~B}$ & P5 & \\
\hline 6 & $\mathrm{C}$ & M3 & \\
\hline 7 & $\mathrm{~A}$ & P8 & \\
\hline 8 & A & M3 & \\
\hline 9 & $\mathrm{~A}$ & $\mathrm{~m} 3$ & \\
\hline 10 & $\mathrm{~A}$ & $\mathrm{~m} 3$ & \\
\hline 10 & B & P4 & \\
\hline 10 & $\mathrm{C}$ & M3 & \\
\hline 11 & $\mathrm{~A}$ & M6 & \\
\hline 11 & $\mathrm{~B}$ & P5 & \\
\hline 12 & $\mathrm{~A}$ & P5 & \\
\hline 13 & $\mathrm{~A}$ & P8 & Bass $\wedge 1$ reconstructed \\
\hline 13 & $\mathrm{~B}$ & M6 & \\
\hline 13 & $\mathrm{C}$ & Dim5 & \\
\hline 14 & $\mathrm{~A}$ & M3 & \\
\hline 16 & A & M7 & \\
\hline 16 & $\mathrm{~B}$ & M6 & \\
\hline 16 & $\mathrm{C}$ & Dim5 & \\
\hline 17 & A & M3 & \\
\hline 18 & A & P5 & \\
\hline 19 & $\mathrm{~A}$ & $\mathrm{~m} 3$ & \\
\hline 19 & $\mathrm{~B}$ & P8 & \\
\hline 20 & A & M6 & \\
\hline 20 & $\mathrm{~B}$ & P4 & \\
\hline
\end{tabular}




\begin{tabular}{|c|c|c|c|}
\hline 20 & $\mathrm{C}$ & M3 & \\
\hline 21 & A & P8 & \\
\hline 22 & $\mathrm{~A}$ & P5 & \\
\hline 23 & $\mathrm{~A}$ & $\mathrm{~m} 3$ & \\
\hline 23 & A & P8 & \\
\hline 24 & A & M6 & \\
\hline 24 & B & P4 & \\
\hline 24 & $\mathrm{C}$ & M3 & \\
\hline 25 & A & P8 & \\
\hline 26 & A & M3 & \\
\hline 27 & A & P5 & \\
\hline 28 & A & P8 & \\
\hline 28 & B & M3 & \\
\hline 29 & A & P5 & \\
\hline 29 & B & P8 & \\
\hline 30 & $\mathrm{~A}$ & M3 & \\
\hline 30 & B & P5 & \\
\hline 31 & A & P5 & \\
\hline 33 & A & P5 & \\
\hline 34 & A & P8 & \\
\hline 34 & B & P5 & \\
\hline 34 & C & M6 & \\
\hline 34 & $\mathrm{D}$ & M7 & \\
\hline 34 & $\mathrm{E}$ & P8 & \\
\hline 34 & $\mathrm{~F}$ & P5 & \\
\hline 34 & $\mathrm{G}$ & M6 & \\
\hline 34 & $\mathrm{H}$ & M7 & \\
\hline 35 & A & P8 & \\
\hline 36 & A & P5 & \\
\hline 37 & A & $\mathrm{m} 3$ & \\
\hline 37 & B & $\mathrm{m} 7$ & \\
\hline 38 & $\mathrm{~A}$ & P5 & \\
\hline 38 & B & P8 & \\
\hline 39 & A & M6 & \\
\hline 39 & B & P5 & \\
\hline 39 & $\mathrm{C}$ & M3 & \\
\hline 40 & A & P5 & \\
\hline 40 & B & P8 & \\
\hline 41 & $\mathrm{~A}$ & M6 & \\
\hline 41 & B & P5 & \\
\hline 41 & $\mathrm{C}$ & M3 & \\
\hline 42 & $\mathrm{~A}$ & P8 & \\
\hline 43 & A & $\mathrm{m} 2$ & \\
\hline 43 & B & P8 & \\
\hline 43 & $\mathrm{C}$ & $\mathrm{m} 7$ & \\
\hline 43 & $\mathrm{D}$ & $\mathrm{m} 2$ & \\
\hline 43 & E & P8 & \\
\hline 43 & $\mathrm{~F}$ & $\mathrm{~m} 7$ & \\
\hline 44 & A & M6 & \\
\hline 45 & A & M2 & \\
\hline 45 & B & P8 & \\
\hline 45 & C & $\mathrm{m} 7$ & \\
\hline 45 & $\mathrm{D}$ & M2 & \\
\hline
\end{tabular}




\begin{tabular}{|c|c|c|c|}
\hline 45 & $\mathrm{E}$ & P8 & \\
\hline 45 & $\mathrm{~F}$ & $\mathrm{~m} 7$ & \\
\hline 46 & A & M3 & \\
\hline 47 & A & M3 & \\
\hline 48 & A & $\mathrm{m} 3$ & \\
\hline 49 & A & $\mathrm{m} 3$ & \\
\hline 49 & B & M3 & \\
\hline 50 & A & P5 & \\
\hline 52 & A & M6 & \\
\hline 52 & B & P5 & \\
\hline 53 & A & P5 & \\
\hline 54 & A & $\mathrm{m} 3$ & \\
\hline 54 & B & P8 & \\
\hline 55 & A & M6 & \\
\hline 55 & B & P4 & \\
\hline 55 & $\mathrm{C}$ & M3 & \\
\hline 56 & A & P8 & \\
\hline 57 & A & M3 & \\
\hline 58 & A & $\mathrm{m} 3$ & \\
\hline 59 & A & Dim5 & \\
\hline 60 & A & M3 & \\
\hline 60 & B & P5 & \\
\hline 61 & A & $\mathrm{m} 3$ & \\
\hline 61 & B & P8 & \\
\hline 62 & A & M6 & \\
\hline 62 & A & P4 & \\
\hline 62 & A & M3 & \\
\hline 63 & A & P8 & \\
\hline 63 & B & P8 & \\
\hline 64 & A & M3 & \\
\hline 65 & $\mathrm{~A}$ & P5 & \\
\hline 66 & A & P8 & \\
\hline 66 & B & M3 & \\
\hline 67 & A & P5 & \\
\hline 67 & B & P8 & \\
\hline 68 & $\mathrm{~A}$ & M3 & \\
\hline 68 & $B$ & P5 & \\
\hline 69 & A & P5 & \\
\hline 70 & $\mathrm{~A}$ & M3 & \\
\hline 70 & B & P5 & \\
\hline 71 & A & P5 & \\
\hline 72 & A & P8 & \\
\hline 72 & B & $\mathrm{m} 7$ & \\
\hline 72 & $\mathrm{C}$ & M6 & \\
\hline 72 & $\mathrm{D}$ & M7 & \\
\hline 73 & A & P8 & \\
\hline 73 & B & $\mathrm{m} 7$ & \\
\hline 73 & $\mathrm{C}$ & M6 & \\
\hline 74 & A & M7 & \\
\hline 74 & B & P8 & \\
\hline
\end{tabular}


Chapter 21 - Leduc

\begin{tabular}{|c|c|c|c|}
\hline Measure number & Position $(\mathrm{a}, \mathrm{b}, \mathrm{c} \ldots)$ & Interval & Comments \\
\hline 1 & $\mathrm{~A}$ & & Unannotated until $\mathrm{m} .6$ \\
\hline 2 & $\mathrm{~A}$ & & \\
\hline 2 & $\mathrm{~B}$ & & \\
\hline 3 & $\mathrm{~A}$ & & \\
\hline 3 & $\mathrm{~B}$ & & \\
\hline 4 & $\mathrm{~A}$ & & \\
\hline 4 & $\mathrm{~B}$ & & \\
\hline 5 & $\mathrm{~A}$ & & \\
\hline 6 & $\mathrm{~A}$ & M3 & \\
\hline 7 & $\mathrm{~A}$ & $\mathrm{~m} 3$ & \\
\hline 8 & $\mathrm{~A}$ & M3 & \\
\hline 8 & $\mathrm{~B}$ & $\operatorname{Dim} 5$ & \\
\hline 8 & $\mathrm{C}$ & M3 & \\
\hline 9 & A & M3 & \\
\hline 9 & $\mathrm{~B}$ & $\operatorname{Dim} 5$ & \\
\hline 9 & $\mathrm{C}$ & M3 & \\
\hline 10 & $\mathrm{~A}$ & M6 & \\
\hline 10 & $\mathrm{~B}$ & P8 & \\
\hline 10 & $\mathrm{C}$ & M3 & \\
\hline 10 & $\mathrm{D}$ & $\operatorname{Dim} 5$ & \\
\hline 11 & A & M3 & \\
\hline 12 & $\mathrm{~A}$ & P5 & \\
\hline 13 & $\mathrm{~A}$ & $\mathrm{~m} 3$ & \\
\hline 15 & $\mathrm{~A}$ & P4 & \\
\hline 15 & $\mathrm{~B}$ & M3 & \\
\hline 16 & $\mathrm{~A}$ & M3 & \\
\hline 17 & $\mathrm{~A}$ & M3 & \\
\hline 17 & $\mathrm{~B}$ & P8 & \\
\hline 17 & $\mathrm{C}$ & M6 & \\
\hline 18 & $\mathrm{~A}$ & M3 & \\
\hline 18 & B & P8 & \\
\hline 18 & $\mathrm{C}$ & M6 & \\
\hline 18 & $\mathrm{D}$ & M3 & \\
\hline 18 & $\mathrm{E}$ & P5 & \\
\hline 19 & $\mathrm{~A}$ & M3 & \\
\hline 23 & $\mathrm{~A}$ & M3 & \\
\hline 23 & $\mathrm{~B}$ & P8 & \\
\hline 24 & $\mathrm{~A}$ & M6 & \\
\hline 25 & $\mathrm{~A}$ & M3 & \\
\hline 25 & $\mathrm{~B}$ & M6 & \\
\hline 26 & $\mathrm{~A}$ & M3 & \\
\hline 26 & $\mathrm{~B}$ & M6 & \\
\hline 27 & $\mathrm{~A}$ & M3 & \\
\hline 28 & $\mathrm{~A}$ & P8 & \\
\hline 28 & $\mathrm{~B}$ & M6 & \\
\hline 28 & $\mathrm{C}$ & Dim5 & \\
\hline 29 & $\mathrm{~A}$ & M3 & \\
\hline 32 & $\mathrm{~A}$ & P5 & \\
\hline 33 & $\mathrm{~A}$ & $\mathrm{P} 4$ & \\
\hline 33 & $\mathrm{~B}$ & M3 & \\
\hline
\end{tabular}




\begin{tabular}{|c|c|c|c|}
\hline 36 & $\mathrm{~A}$ & M6 & \\
\hline 36 & B & P5 & \\
\hline 37 & $\mathrm{~A}$ & P8 & \\
\hline 42 & $\mathrm{~A}$ & M3 & \\
\hline 42 & $\mathrm{~B}$ & $\mathrm{~m} 6$ & \\
\hline 43 & A & M3 & \\
\hline 43 & B & $\mathrm{m} 6$ & \\
\hline 44 & A & Dim5 & \\
\hline 45 & A & M3 & \\
\hline 45 & $\mathrm{~B}$ & P8 & \\
\hline 45 & $\mathrm{C}$ & M6 & \\
\hline 45 & $\mathrm{D}$ & P5 & \\
\hline 46 & A & P8 & \\
\hline 47 & A & & Unmarked until m. 54 \\
\hline 48 & $\mathrm{~A}$ & & \\
\hline 48 & $\mathrm{~B}$ & & \\
\hline 49 & A & & \\
\hline 49 & $\mathrm{~B}$ & & \\
\hline 50 & A & & \\
\hline 50 & $\mathrm{~B}$ & & \\
\hline 51 & A & & \\
\hline 54 & A & $\mathrm{m} 3$ & \\
\hline 54 & $\mathrm{~B}$ & Dim5 & \\
\hline 55 & A & M3 & \\
\hline 59 & A & $\mathrm{m} 6$ & \\
\hline 59 & $\mathrm{~B}$ & Dim5 & \\
\hline 60 & A & $\mathrm{m} 3$ & \\
\hline 60 & $\mathrm{~B}$ & P8 & \\
\hline 60 & $\mathrm{C}$ & M6 & \\
\hline 61 & A & M6 & \\
\hline 61 & $\mathrm{~B}$ & $\mathrm{~m} 6$ & \\
\hline 61 & $\mathrm{C}$ & Dim5 & \\
\hline 62 & A & $\mathrm{m} 3$ & \\
\hline 62 & $\mathrm{~B}$ & P8 & \\
\hline 62 & $\mathrm{C}$ & M6 & \\
\hline 63 & A & M6 & \\
\hline 64 & A & $\mathrm{P} 4$ & \\
\hline 64 & $\mathrm{~B}$ & $\mathrm{~m} 3$ & \\
\hline 66 & A & P4 & \\
\hline 66 & $\mathrm{~B}$ & M3 & \\
\hline 67 & A & $\mathrm{m} 3$ & \\
\hline 68 & A & $\mathrm{m} 3$ & \\
\hline 68 & $\mathrm{~B}$ & Dim5 & \\
\hline 69 & A & M3 & \\
\hline 70 & A & M6 & \\
\hline 71 & A & $\mathrm{m} 6$ & \\
\hline 72 & A & M6 & \\
\hline 72 & B & P8 & \\
\hline 72 & C & M3 & \\
\hline 72 & D & Dim5 & \\
\hline 73 & A & M3 & \\
\hline 76 & A & Aug6 & \\
\hline 77 & $\mathrm{~A}$ & P8 & \\
\hline
\end{tabular}




\begin{tabular}{|c|c|c|c|}
\hline 78 & $\mathrm{~A}$ & P8 & \\
\hline 78 & $\mathrm{~B}$ & $\mathrm{P} 8$ & \\
\hline 78 & $\mathrm{C}$ & M3 & \\
\hline 78 & $\mathrm{D}$ & $\mathrm{P} 5$ & \\
\hline 78 & $\mathrm{E}$ & $\mathrm{m} 7$ & \\
\hline 78 & $\mathrm{~F}$ & P8 & \\
\hline 79 & $\mathrm{~A}$ & P8 & \\
\hline 79 & $\mathrm{~B}$ & & Unmarked until m. 84 \\
\hline 80 & $\mathrm{~A}$ & & \\
\hline 80 & $\mathrm{~B}$ & & \\
\hline 81 & $\mathrm{~A}$ & & \\
\hline 81 & $\mathrm{~B}$ & & \\
\hline 82 & $\mathrm{~A}$ & & \\
\hline 82 & $\mathrm{~B}$ & & \\
\hline 83 & $\mathrm{~A}$ & & \\
\hline 84 & $\mathrm{~A}$ & M3 & \\
\hline 85 & $\mathrm{~A}$ & $\mathrm{~m} 3$ & \\
\hline 86 & $\mathrm{~A}$ & M3 & \\
\hline 86 & B & Dim5 & \\
\hline 86 & $\mathrm{C}$ & M3 & \\
\hline 87 & $\mathrm{~A}$ & M3 & \\
\hline 87 & B & Dim5 & \\
\hline 87 & $\mathrm{C}$ & M3 & \\
\hline 88 & A & M6 & \\
\hline 88 & B & P8 & \\
\hline 88 & $\mathrm{C}$ & M3 & \\
\hline 88 & $\mathrm{D}$ & Dim5 & \\
\hline 89 & A & M3 & \\
\hline 95 & A & M3 & \\
\hline 95 & B & M6 & \\
\hline 96 & A & M3 & \\
\hline 96 & B & M6 & \\
\hline 97 & A & M3 & \\
\hline 103 & A & P4 & \\
\hline 103 & B & M3 & \\
\hline 106 & A & M6 & \\
\hline 106 & B & P5 & \\
\hline 107 & A & P8 & \\
\hline 112 & A & M3 & \\
\hline 112 & B & $\mathrm{m} 6$ & \\
\hline 113 & A & M3 & \\
\hline 113 & B & $\mathrm{m} 6$ & \\
\hline 114 & A & Dim5 & \\
\hline 115 & $\mathrm{a}$ & M3 & \\
\hline 115 & B & P8 & \\
\hline 115 & C & M6 & \\
\hline 115 & $\mathrm{D}$ & Dim5 & \\
\hline 116 & A & $\mathrm{m} 3$ & \\
\hline 116 & B & M6 & \\
\hline 116 & $\mathrm{C}$ & P5 & \\
\hline 117 & $\mathrm{~A}$ & P8 & \\
\hline
\end{tabular}


Chapter 22 - Leo

\begin{tabular}{|c|c|c|c|}
\hline Measure number & Position $(\mathrm{a}, \mathrm{b}, \mathrm{c} \ldots)$ & Interval & Comments \\
\hline 2 & $\mathrm{~A}$ & M6 & \\
\hline 3 & $\mathrm{~A}$ & $\mathrm{P} 5$ & \\
\hline 3 & $\mathrm{~B}$ & P8 & \\
\hline 4 & $\mathrm{~A}$ & M3 & \\
\hline 4 & $\mathrm{~B}$ & $\mathrm{~m} 7$ & \\
\hline 5 & $\mathrm{~A}$ & M6 & \\
\hline 5 & $\mathrm{~B}$ & $\mathrm{P} 5$ & \\
\hline 6 & $\mathrm{~A}$ & $\mathrm{~m} 6$ & \\
\hline 7 & $\mathrm{~A}$ & P5 & \\
\hline 8 & A & P4 & \\
\hline 9 & $\mathrm{~A}$ & $\mathrm{~m} 3$ & \\
\hline 9 & $\mathrm{~B}$ & Dim5 & \\
\hline 10 & A & M3 & \\
\hline 10 & $\mathrm{~B}$ & M2 & \\
\hline 10 & $\mathrm{C}$ & $\mathrm{m} 3$ & \\
\hline 10 & $\mathrm{D}$ & $\mathrm{m} 3$ & \\
\hline 10 & $\mathrm{E}$ & M3 & \\
\hline 10 & $\mathrm{~F}$ & $\mathrm{~m} 3$ & \\
\hline 12 & A & M3 & \\
\hline 12 & $\mathrm{~B}$ & P8 & \\
\hline 12 & $\mathrm{C}$ & $\mathrm{m} 7$ & \\
\hline 12 & $\mathrm{D}$ & M3 & \\
\hline 12 & $\mathrm{E}$ & $\mathrm{m} 3$ & \\
\hline 14 & $\mathrm{~A}$ & M3 & \\
\hline 14 & $\mathrm{~B}$ & P8 & \\
\hline 14 & $\mathrm{C}$ & $\mathrm{m} 7$ & \\
\hline 14 & $\mathrm{D}$ & M6 & \\
\hline 14 & E & P5 & \\
\hline 15 & $\mathrm{~A}$ & M6 & \\
\hline 15 & $\mathrm{~B}$ & P5 & \\
\hline 16 & $\mathrm{~A}$ & P8 & \\
\hline 19 & $\mathrm{~A}$ & M3 & \\
\hline 20 & $\mathrm{~A}$ & $\mathrm{~m} 3$ & \\
\hline 20 & $\mathrm{~B}$ & $\mathrm{P} 8$ & \\
\hline 21 & $\mathrm{~A}$ & M3 & \\
\hline 21 & $\mathrm{~B}$ & $\mathrm{~m} 7$ & \\
\hline 22 & $\mathrm{~A}$ & M3 & \\
\hline 23 & $\mathrm{~A}$ & M3 & \\
\hline 24 & $\mathrm{~A}$ & P5 & \\
\hline 24 & $\mathrm{~B}$ & P8 & \\
\hline 25 & $\mathrm{~A}$ & M6 & \\
\hline 25 & $\mathrm{~B}$ & $\mathrm{~m} 3$ & \\
\hline 25 & $\mathrm{C}$ & M3 & \\
\hline 26 & $\mathrm{~A}$ & M6 & \\
\hline 26 & $\mathrm{~B}$ & P5 & \\
\hline 27 & $\mathrm{~A}$ & Dim5 & \\
\hline 28 & $\mathrm{~A}$ & M3 & \\
\hline 29 & $\mathrm{~A}$ & Dim5 & \\
\hline 30 & $\mathrm{~A}$ & M3 & \\
\hline 32 & $\mathrm{~A}$ & P4 & \\
\hline
\end{tabular}




\begin{tabular}{|c|c|c|c|}
\hline 32 & B & M3 & \\
\hline 33 & A & $\mathrm{m} 6$ & \\
\hline 34 & $\mathrm{~A}$ & P5 & \\
\hline 35 & A & \begin{tabular}{|l|} 
P4 \\
\end{tabular} & \\
\hline 36 & A & $\mathrm{m} 3$ & \\
\hline 36 & $\mathrm{~B}$ & Dim5 & \\
\hline 37 & $\mathrm{~A}$ & M3 & \\
\hline 38 & A & M3 & \\
\hline 38 & B & P8 & \\
\hline 38 & $\mathrm{C}$ & $\mathrm{m} 7$ & \\
\hline 38 & $\mathrm{D}$ & M6 & \\
\hline 38 & $E$ & P5 & \\
\hline 40 & $\mathrm{~A}$ & M3 & \\
\hline 40 & B & P8 & \\
\hline 40 & $\mathrm{C}$ & $\mathrm{m} 7$ & \\
\hline 40 & $\mathrm{D}$ & M6 & \\
\hline 40 & $E$ & P5 & \\
\hline 42 & $\mathrm{~A}$ & M3 & \\
\hline 42 & B & P8 & \\
\hline 42 & $\mathrm{C}$ & $\mathrm{m} 7$ & \\
\hline 42 & $\mathrm{D}$ & M6 & \\
\hline 42 & $E$ & P5 & \\
\hline 43 & $\mathrm{~A}$ & $\mathrm{~m} 6$ & \\
\hline 44 & $\mathrm{~A}$ & M3 & \\
\hline 44 & $\mathrm{~B}$ & M2 & \\
\hline 44 & $\mathrm{C}$ & P8 & \\
\hline 44 & $\mathrm{D}$ & M6 & \\
\hline 44 & $E$ & P5 & \\
\hline 45 & $\mathrm{~A}$ & P8 & \\
\hline 46 & $\mathrm{~A}$ & P8 & \\
\hline 47 & $\mathrm{~A}$ & M3 & \\
\hline 47 & B & $\mathrm{m} 7$ & \\
\hline 48 & $\mathrm{~A}$ & M6 & \\
\hline 48 & B & P5 & \\
\hline 50 & $\mathrm{~A}$ & Dim5 & \\
\hline 50 & B & M3 & \\
\hline 51 & $\mathrm{~A}$ & Dim5 & \\
\hline 52 & B & $\mathrm{m} 3$ & \\
\hline 53 & $\mathrm{~A}$ & Dim5 & \\
\hline 54 & $\mathrm{~A}$ & M3 & \\
\hline 55 & $\mathrm{~A}$ & M3 & \\
\hline 56 & $\mathrm{~A}$ & m3 & \\
\hline 58 & $\mathrm{~A}$ & M6 & \\
\hline 58 & B & Dim5 & \\
\hline 59 & $\mathrm{~A}$ & M3 & \\
\hline 60 & $\mathrm{~A}$ & Dim5 & \\
\hline 61 & $\mathrm{~A}$ & M3 & \\
\hline 62 & $\mathrm{~A}$ & Dim5 & \\
\hline 63 & A & M3 & \\
\hline 64 & $\mathrm{~A}$ & Dim5 & \\
\hline 65 & $\mathrm{~A}$ & m3 & \\
\hline 66 & $\mathrm{~A}$ & m3 & \\
\hline 68 & A & M3 & \\
\hline
\end{tabular}




\begin{tabular}{|c|c|c|c|}
\hline 69 & $\mathrm{~A}$ & $\mathrm{~m} 6$ & \\
\hline 71 & A & M3 & \\
\hline 72 & $\mathrm{~A}$ & $\mathrm{~m} 6$ & \\
\hline 73 & $\mathrm{~A}$ & P5 & \\
\hline 74 & A & P4 & \\
\hline 75 & $\mathrm{~A}$ & $\mathrm{~m} 3$ & \\
\hline 75 & B & Dim5 & \\
\hline 76 & A & M3 & \\
\hline 77 & A & Dim5 & \\
\hline 78 & A & M3 & \\
\hline 79 & A & M3 & \\
\hline 79 & B & P8 & \\
\hline 79 & $\mathrm{C}$ & $\mathrm{m} 7$ & \\
\hline 79 & D & M6 & \\
\hline 79 & E & P5 & \\
\hline 81 & A & M3 & \\
\hline 81 & B & P8 & \\
\hline 81 & C & $\mathrm{m} 7$ & \\
\hline 81 & D & M6 & \\
\hline 81 & $\mathrm{E}$ & P5 & \\
\hline 83 & A & M3 & \\
\hline 83 & B & P8 & \\
\hline 83 & C & $\mathrm{m} 7$ & \\
\hline 83 & D & M6 & \\
\hline 83 & $E$ & P5 & \\
\hline 86 & A & P5 & \\
\hline 87 & A & P8 & \\
\hline 87 & B & P8 & \\
\hline 88 & A & M3 & \\
\hline 88 & B & $\mathrm{m} 7$ & \\
\hline 89 & A & M3 & \\
\hline 89 & B & M6 & \\
\hline 89 & C & P5 & \\
\hline 90 & A & P8 & \\
\hline 91 & A & P8 & \\
\hline 92 & A & P5 & \\
\hline 93 & A & $\mathrm{m} 3$ & \\
\hline 94 & A & $\mathrm{m} 3$ & \\
\hline 95 & A & $\mathrm{m} 3$ & \\
\hline 97 & A & $\mathrm{m} 3$ & \\
\hline 97 & B & P8 & \\
\hline 97 & C & $\mathrm{m} 7$ & \\
\hline 97 & D & $\mathrm{m} 6$ & \\
\hline 97 & $E$ & P5 & \\
\hline 99 & A & $\mathrm{m} 3$ & \\
\hline 99 & B & P8 & \\
\hline 99 & C & $\mathrm{m} 7$ & \\
\hline 99 & $\mathrm{D}$ & $\mathrm{m} 6$ & \\
\hline 99 & $\mathrm{E}$ & P5 & \\
\hline 102 & A & $\mathrm{m} 6$ & \\
\hline 102 & B & P5 & \\
\hline 103 & A & P8 & \\
\hline 105 & $\mathrm{~A}$ & M3 & \\
\hline
\end{tabular}




\begin{tabular}{|l|l|l|l|}
\hline 106 & A & m3 & \\
\hline 106 & B & P8 & \\
\hline 107 & A & M3 & \\
\hline 107 & B & m7 & \\
\hline 108 & A & M3 & \\
\hline 108 & B & M6 & \\
\hline 108 & C & P5 & \\
\hline 109 & A & P8 & \\
\hline
\end{tabular}

Chapter 23 - Galuppi aria

\begin{tabular}{|c|c|c|c|}
\hline Measure number & Position $(\mathrm{a}, \mathrm{b}, \mathrm{c} \ldots)$ & Interval & Comments \\
\hline 1 & A & P5 & \\
\hline 2 & A & $\mathrm{m} 3$ & \\
\hline 2 & $\mathrm{~B}$ & $\mathrm{~m} 3$ & \\
\hline 3 & A & M3 & \\
\hline 3 & $\mathrm{~B}$ & $\mathrm{~m} 3$ & \\
\hline 3 & $\mathrm{C}$ & $\mathrm{m} 3$ & \\
\hline 3 & $\mathrm{D}$ & M3 & \\
\hline 4 & A & M6 & \\
\hline 4 & $\mathrm{~B}$ & $\mathrm{P} 5$ & \\
\hline 7 & A & M6 & \\
\hline 7 & B & P5 & \\
\hline 8 & $\mathrm{~A}$ & P8 & \\
\hline 9 & $\mathrm{~A}$ & $\mathrm{P} 5$ & \\
\hline 10 & A & $\mathrm{m} 3$ & \\
\hline 10 & B & $\mathrm{m} 3$ & \\
\hline 11 & A & M3 & \\
\hline 11 & B & $\mathrm{m} 3$ & \\
\hline 11 & $\mathrm{C}$ & $\mathrm{m} 3$ & \\
\hline 11 & $\mathrm{D}$ & M3 & \\
\hline 12 & A & M6 & \\
\hline 12 & B & P5 & \\
\hline 14 & A & M3 & \\
\hline 14 & B & $\mathrm{m} 3$ & \\
\hline 14 & $\mathrm{C}$ & Dim5 & \\
\hline 15 & A & M3 & \\
\hline 15 & $\mathrm{~B}$ & P8 & \\
\hline 15 & $\mathrm{C}$ & M6 & \\
\hline 15 & $\mathrm{D}$ & P5 & \\
\hline 16 & A & P8 & \\
\hline 17 & A & $\mathrm{m} 3$ & \\
\hline 17 & $\mathrm{~B}$ & $\mathrm{~m} 3$ & \\
\hline 18 & A & $\mathrm{m} 3$ & \\
\hline 18 & B & M3 & \\
\hline 19 & A & M3 & \\
\hline 19 & $\mathrm{~B}$ & $\mathrm{~m} 3$ & \\
\hline 19 & $\mathrm{C}$ & $\mathrm{m} 3$ & \\
\hline 19 & $\mathrm{D}$ & M3 & \\
\hline 20 & A & M6 & \\
\hline 20 & $\mathrm{~B}$ & P5 & \\
\hline 20 & $\mathrm{C}$ & M3 & \\
\hline 21 & A & M3 & \\
\hline 21 & B & $\mathrm{m} 7$ & \\
\hline
\end{tabular}




\begin{tabular}{|c|c|c|c|}
\hline 22 & $\mathrm{~A}$ & $\mathrm{~m} 3$ & \\
\hline 22 & B & P5 & \\
\hline 23 & A & M3 & \\
\hline 23 & $\mathrm{~B}$ & $\mathrm{~m} 7$ & \\
\hline 24 & A & M3 & \\
\hline 25 & A & $\mathrm{m} 7$ & \\
\hline 25 & B & $\mathrm{m} 6$ & \\
\hline 25 & $\mathrm{C}$ & Dim5 & \\
\hline 26 & A & M3 & \\
\hline 28 & A & M3 & with reconstructed bass ${ }^{\wedge} 4$ \\
\hline 29 & A & $\mathrm{m} 3$ & \\
\hline 29 & B & $\mathrm{m} 3$ & \\
\hline 30 & $\mathrm{~A}$ & M3 & \\
\hline 30 & B & P8 & \\
\hline 30 & $\mathrm{C}$ & P8 & \\
\hline 31 & A & $\mathrm{m} 6$ & \\
\hline 31 & B & M7 & \\
\hline 31 & $\mathrm{C}$ & P5 & \\
\hline 32 & A & P8 & \\
\hline 33 & A & P8 & \\
\hline 33 & $\mathrm{~B}$ & M6 & \\
\hline 33 & $\mathrm{C}$ & P5 & \\
\hline 34 & A & P8 & \\
\hline
\end{tabular}

Chapter 24 - Jommelli

\begin{tabular}{|l|l|l|l|}
\hline Measure number & Position $(\mathrm{a}, \mathrm{b}, \mathrm{c} \ldots)$ & Interval & Comments \\
\hline 1 & A & P8 & \\
\hline 2 & A & m3 & \\
\hline 2 & B & m6 & \\
\hline 3 & A & M3 & \\
\hline 3 & B & P5 & \\
\hline 4 & A & m7 & \\
\hline 4 & B & M6 & \\
\hline 4 & C & P5 & \\
\hline 5 & A & P8 & \\
\hline 6 & A & M3 & \\
\hline 7 & A & m3 & \\
\hline 7 & B & Dim5 & \\
\hline 8 & A & M3 & \\
\hline 8 & B & m7 & \\
\hline 9 & A & P5 & \\
\hline 9 & B & P8 & \\
\hline 9 & C & M6 & \\
\hline 9 & D & P5 & \\
\hline 10 & A & P8 & \\
\hline 11 & A & P8 & \\
\hline 12 & A & m3 & \\
\hline 12 & B & m6 & \\
\hline 13 & A & M3 & \\
\hline 13 & B & P5 & \\
\hline 14 & A & m7 & \\
\hline 14 & B & M 6 & \\
\hline 14 & & P5 & \\
\hline & & & \\
\hline
\end{tabular}




\begin{tabular}{|c|c|c|c|}
\hline 16 & $\mathrm{~A}$ & M3 & \\
\hline 17 & $\mathrm{~A}$ & $\mathrm{~m} 3$ & \\
\hline 17 & $\mathrm{~B}$ & Dim5 & \\
\hline 18 & A & M3 & \\
\hline 18 & $\mathrm{~B}$ & $\mathrm{~m} 7$ & \\
\hline 19 & A & P5 & \\
\hline 19 & B & P8 & \\
\hline 19 & $\mathrm{C}$ & M6 & \\
\hline 19 & $\mathrm{D}$ & P5 & \\
\hline 20 & A & P8 & \\
\hline 20 & B & P5 & \\
\hline 21 & A & M6 & \\
\hline 22 & A & P5 & \\
\hline 22 & B & P5 & \\
\hline 23 & A & $\mathrm{m} 6$ & \\
\hline 24 & A & P5 & \\
\hline 24 & B & P5 & \\
\hline 25 & A & $\mathrm{m} 6$ & \\
\hline 25 & B & M7 & \\
\hline 26 & A & P8 & \\
\hline 26 & B & $\mathrm{P} 5$ & \\
\hline 28 & A & M3 & \\
\hline 29 & A & Dim5 & \\
\hline 30 & A & $\mathrm{m} 3$ & \\
\hline 31 & A & Dim5 & \\
\hline 32 & A & $\mathrm{m} 7$ & \\
\hline 32 & $\mathrm{~B}$ & P5 & \\
\hline 32 & $\mathrm{C}$ & $\mathrm{m} 7$ & \\
\hline 33 & A & P5 & \\
\hline 33 & B & P8 & \\
\hline 33 & $\mathrm{C}$ & M6 & \\
\hline 33 & D & P5 & \\
\hline 34 & A & P8 & \\
\hline 34 & B & P5 & \\
\hline 35 & A & $\mathrm{m} 6$ & \\
\hline 35 & B & M7 & \\
\hline 36 & A & P8 & \\
\hline 36 & B & P5 & \\
\hline 36 & C & P5 & \\
\hline 37 & A & $\mathrm{m} 6$ & \\
\hline 37 & B & M7 & \\
\hline 38 & A & P8 & \\
\hline 40 & A & M3 & \\
\hline 41 & A & Dim5 & \\
\hline 42 & A & $\mathrm{m} 3$ & \\
\hline 43 & A & Dim5 & \\
\hline 44 & A & $\mathrm{m} 7$ & \\
\hline 44 & B & P5 & \\
\hline 44 & C & $\mathrm{m} 7$ & \\
\hline 45 & A & $\mathrm{P} 5$ & \\
\hline 45 & B & P8 & \\
\hline 45 & C & M6 & \\
\hline 44 & $\mathrm{D}$ & $\mathrm{P5}$ & \\
\hline
\end{tabular}




\begin{tabular}{|c|c|c|c|}
\hline 49 & $\mathrm{~A}$ & P8 & \\
\hline 49 & B & M6 & \\
\hline 49 & $\mathrm{C}$ & P5 & \\
\hline 52 & $\mathrm{~A}$ & $\mathrm{~m} 7$ & \\
\hline 52 & $\mathrm{~B}$ & P5 & \\
\hline 53 & A & P8 & \\
\hline 53 & B & M6 & \\
\hline 53 & $\mathrm{C}$ & P5 & \\
\hline 54 & A & P8 & \\
\hline 56 & A & M3 & \\
\hline 56 & B & P4 & Missing note, cf. m. 57 \\
\hline 56 & $\mathrm{C}$ & M3 & \\
\hline 57 & $\mathrm{~A}$ & M3 & \\
\hline 57 & $\mathrm{~B}$ & $\mathrm{P} 4$ & \\
\hline 57 & $\mathrm{C}$ & M3 & \\
\hline 58 & A & P8 & \\
\hline 59 & A & Dim5 & \\
\hline 60 & A & $\mathrm{m} 3$ & \\
\hline 61 & A & Dim5 & \\
\hline 62 & A & M3 & \\
\hline 62 & $\mathrm{~B}$ & P8 & \\
\hline 63 & A & $\mathrm{m} 3$ & \\
\hline 63 & $\mathrm{~B}$ & $\mathrm{~m} 6$ & \\
\hline 64 & A & M3 & \\
\hline 64 & $\mathrm{~B}$ & P5 & \\
\hline 65 & A & $\mathrm{m} 7$ & \\
\hline 65 & $\mathrm{~B}$ & M6 & \\
\hline 65 & $\mathrm{C}$ & P5 & \\
\hline 66 & A & P8 & \\
\hline 66 & $\mathrm{~B}$ & P8 & \\
\hline 67 & A & $\mathrm{m} 3$ & \\
\hline 67 & $\mathrm{~B}$ & $\mathrm{~m} 6$ & \\
\hline 68 & A & M3 & \\
\hline 68 & $\mathrm{~B}$ & P5 & \\
\hline 69 & A & $\mathrm{m} 7$ & \\
\hline 69 & $\mathrm{~B}$ & M6 & \\
\hline 69 & $\mathrm{C}$ & P5 & \\
\hline 70 & A & P8 & \\
\hline 70 & $\mathrm{~B}$ & $\mathrm{~m} 7$ & \\
\hline 71 & A & M3 & \\
\hline 71 & $\mathrm{~B}$ & $\mathrm{~m} 7$ & \\
\hline 72 & A & M3 & \\
\hline 72 & B & M3 & \\
\hline 73 & A & M3 & \\
\hline 73 & $\mathrm{~B}$ & $\mathrm{~m} 7$ & \\
\hline 74 & A & P5 & \\
\hline 74 & B & M3 & \\
\hline 75 & A & M3 & \\
\hline 75 & B & M3 & \\
\hline 76 & A & M3 & \\
\hline 78 & A & M3 & \\
\hline 79 & A & Dim5 & \\
\hline 80 & $\mathrm{~A}$ & $\mathrm{~m} 3$ & \\
\hline
\end{tabular}




\begin{tabular}{|c|c|c|c|}
\hline 81 & $\mathrm{~A}$ & Dim5 & \\
\hline 82 & $\mathrm{~A}$ & $\mathrm{~m} 7$ & \\
\hline 82 & $B$ & P5 & \\
\hline 82 & $\mathrm{C}$ & $\mathrm{m} 7$ & \\
\hline 83 & A & P5 & \\
\hline 83 & $B$ & P8 & \\
\hline 83 & $\mathrm{C}$ & M6 & \\
\hline 83 & $\mathrm{D}$ & P5 & \\
\hline 84 & A & P8 & \\
\hline 84 & $B$ & $\mathrm{~m} 7$ & \\
\hline 85 & A & M3 & \\
\hline 85 & B & Dim5 & \\
\hline 86 & A & M3 & \\
\hline 92 & A & M3 & \\
\hline 93 & A & Dim5 & \\
\hline 94 & $\mathrm{~A}$ & $\mathrm{~m} 3$ & \\
\hline 95 & A & Dim5 & \\
\hline 96 & A & $\mathrm{m} 7$ & \\
\hline 96 & B & P5 & \\
\hline 96 & $\mathrm{C}$ & $\mathrm{m} 7$ & \\
\hline 97 & $\mathrm{~A}$ & P5 & \\
\hline 97 & $B$ & P8 & \\
\hline 97 & $\mathrm{C}$ & M6 & \\
\hline 97 & $\mathrm{D}$ & $\mathrm{P} 5$ & \\
\hline 101 & $\mathrm{~A}$ & P8 & \\
\hline 101 & B & M6 & \\
\hline 101 & $\mathrm{C}$ & P5 & \\
\hline 106 & $\mathrm{~A}$ & P8 & \\
\hline 106 & B & M6 & \\
\hline 106 & $\mathrm{C}$ & P5 & \\
\hline 107 & $\mathrm{~A}$ & P8 & \\
\hline 108 & $\mathrm{~A}$ & M3 & \\
\hline 108 & $B$ & $\mathrm{~m} 6$ & \\
\hline 108 & $\mathrm{C}$ & Dim5 & \\
\hline 109 & $\mathrm{~A}$ & M3 & \\
\hline 109 & $B$ & M3 & \\
\hline 109 & $\mathrm{C}$ & P4 & \\
\hline 109 & $\mathrm{D}$ & M3 & \\
\hline 110 & $\mathrm{~A}$ & M3 & \\
\hline 110 & B & P4 & \\
\hline 110 & $\mathrm{C}$ & M3 & \\
\hline 111 & $\mathrm{~A}$ & P8 & \\
\hline 112 & A & P8 & \\
\hline 112 & B & M3 & \\
\hline 112 & $\mathrm{C}$ & P5 & \\
\hline 113 & A & P5 & \\
\hline 113 & B & M3 & \\
\hline 113 & $\mathrm{C}$ & P5 & \\
\hline 114 & A & P5 & \\
\hline 114 & B & M3 & \\
\hline 114 & $\mathrm{C}$ & Dim5 & \\
\hline 114 & $\mathrm{D}$ & M3 & \\
\hline 115 & $\mathrm{~A}$ & M6 & \\
\hline
\end{tabular}




\begin{tabular}{|c|c|c|c|}
\hline 115 & $\mathrm{~B}$ & P5 & \\
\hline 117 & A & Dim5 & \\
\hline 117 & B & $\mathrm{m} 3$ & \\
\hline 117 & $\mathrm{C}$ & $\mathrm{m} 7$ & \\
\hline 118 & A & M3 & \\
\hline 118 & B & P5 & \\
\hline 118 & $\mathrm{C}$ & $\mathrm{m} 7$ & \\
\hline 118 & $\mathrm{D}$ & M3 & \\
\hline 118 & $E$ & P5 & \\
\hline 118 & $\mathrm{~F}$ & $\mathrm{~m} 7$ & \\
\hline 119 & A & P5 & \\
\hline 119 & B & $\mathrm{m} 7$ & \\
\hline 119 & $\mathrm{C}$ & M3 & \\
\hline 120 & A & Dim5 & \\
\hline 120 & B & $\mathrm{m} 3$ & \\
\hline 121 & A & Dim5 & \\
\hline 121 & B & $\operatorname{Dim} 5$ & \\
\hline 122 & A & Dim5 & \\
\hline 122 & B & M3 & \\
\hline 123 & A & $\mathrm{m} 3$ & \\
\hline 123 & B & P8 & \\
\hline 123 & C & M6 & \\
\hline 123 & $\mathrm{D}$ & P5 & \\
\hline 123 & $\mathrm{E}$ & P8 & \\
\hline 124 & A & P5 & \\
\hline 124 & B & $\mathrm{m} 7$ & \\
\hline 124 & C & M3 & \\
\hline 124 & D & $\mathrm{m} 7$ & \\
\hline 125 & A & M3 & \\
\hline 126 & A & P5 & \\
\hline 126 & B & $\mathrm{m} 7$ & \\
\hline 127 & A & P5 & \\
\hline 127 & B & $\mathrm{m} 7$ & \\
\hline 127 & $\mathrm{C}$ & M3 & \\
\hline 128 & A & Dim5 & \\
\hline 128 & B & $\mathrm{m} 3$ & \\
\hline 129 & A & Dim5 & \\
\hline 129 & B & Dim5 & \\
\hline 130 & $\mathrm{~A}$ & Dim5 & \\
\hline 130 & B & M3 & \\
\hline 131 & A & P8 & \\
\hline 131 & B & $\mathrm{m} 7$ & \\
\hline 132 & A & M3 & \\
\hline 132 & B & P8 & \\
\hline 132 & $\mathrm{C}$ & $\mathrm{m} 7$ & \\
\hline 132 & D & M3 & \\
\hline 137 & A & M6 & \\
\hline 137 & B & P5 & \\
\hline 138 & A & M6 & \\
\hline 138 & B & P5 & \\
\hline 139 & A & P8 & \\
\hline 140 & A & $\mathrm{m} 3$ & \\
\hline 140 & $\mathrm{~B}$ & $\mathrm{~m} 6$ & \\
\hline
\end{tabular}




\begin{tabular}{|l|l|l|l|}
\hline 140 & C & M3 & \\
\hline 140 & D & M6 & \\
\hline 141 & A & m6 & \\
\hline 141 & B & P5 & \\
\hline 143 & A & m3 & \\
\hline 144 & A & P8 & \\
\hline 144 & B & Dim5 & \\
\hline
\end{tabular}

Chapter 26 - Mozart

\begin{tabular}{|c|c|c|c|}
\hline Measure number & Position $(\mathrm{a}, \mathrm{b}, \mathrm{c} \ldots)$ & Interval & Comments \\
\hline 3 & $\mathrm{~A}$ & M3 & \\
\hline 3 & $\mathrm{~B}$ & $\mathrm{~m} 3$ & \\
\hline 4 & $\mathrm{~A}$ & $\mathrm{~m} 3$ & \\
\hline 4 & $\mathrm{~B}$ & M3 & \\
\hline 5 & $\mathrm{~A}$ & M3 & \\
\hline 6 & A & $\mathrm{m} 3$ & \\
\hline 7 & $\mathrm{~A}$ & $\mathrm{~m} 3$ & \\
\hline 8 & $\mathrm{~A}$ & M3 & \\
\hline 9 & A & M6 & \\
\hline 9 & B & M6 & \\
\hline 10 & $\mathrm{~A}$ & M3 & \\
\hline 10 & B & $\mathrm{m} 6$ & \\
\hline 10 & $\mathrm{C}$ & P8 & \\
\hline 10 & $\mathrm{D}$ & Dim5 & \\
\hline 11 & A & M3 & \\
\hline 14 & A & $\mathrm{m} 6$ & \\
\hline 15 & A & Aug4 & \\
\hline 16 & A & $\mathrm{m} 6$ & \\
\hline 17 & A & Aug4 & \\
\hline 18 & A & M3 & \\
\hline 19 & A & $\mathrm{m} 3$ & \\
\hline 20 & A & $\mathrm{m} 3$ & \\
\hline 21 & A & M3 & \\
\hline 22 & A & M6 & \\
\hline 22 & B & P8 & \\
\hline 22 & $\mathrm{C}$ & M3 & \\
\hline 23 & $\mathrm{~A}$ & M6 & \\
\hline 24 & $\mathrm{~A}$ & M6 & \\
\hline 25 & A & P5 & \\
\hline 26 & $\mathrm{~A}$ & P8 & \\
\hline 31 & $\mathrm{~A}$ & P5 & \\
\hline 32 & A & M3 & \\
\hline 32 & B & m7 & \\
\hline 33 & $\mathrm{~A}$ & m3 & \\
\hline 35 & A & P4 & \\
\hline 36 & $\mathrm{~A}$ & $\mathrm{~m} 3$ & \\
\hline 36 & B & M6 & \\
\hline 37 & A & M6 & \\
\hline 37 & B & $\mathrm{m} 3$ & \\
\hline 38 & $\mathrm{~A}$ & M3 & \\
\hline 39 & A & $\mathrm{m} 3$ & \\
\hline 40 & A & $\mathrm{m} 3$ & \\
\hline 44 & $\mathrm{~A}$ & M3 & \\
\hline
\end{tabular}




\begin{tabular}{|l|l|l|l|}
\hline 44 & B & m3 & \\
\hline 45 & A & m3 & \\
\hline 45 & B & M3 & \\
\hline 46 & A & M3 & \\
\hline 47 & A & m3 & \\
\hline 48 & A & m3 & \\
\hline 49 & A & M3 & \\
\hline 50 & A & M3 & \\
\hline 51 & A & m3 & \\
\hline 52 & A & m3 & \\
\hline 53 & A & M3 & \\
\hline 54 & A & M6 & \\
\hline 54 & B & M6 & \\
\hline 55 & A & M3 & \\
\hline 55 & B & m6 & \\
\hline 55 & C & P8 & \\
\hline 55 & D & Dim5 & \\
\hline 56 & A & M3 & \\
\hline 59 & A & m6 & \\
\hline 60 & A & Aug4 & \\
\hline 61 & A & m6 & \\
\hline 62 & A & Aug4 & \\
\hline 63 & A & M3 & \\
\hline 64 & A & m3 & \\
\hline 65 & A & m3 & \\
\hline 66 & A & M3 & \\
\hline 67 & A & M6 & \\
\hline 68 & A & m3 & \\
\hline 69 & & P5 & \\
\hline 70 & P & & \\
\hline 71 & & P & \\
\hline
\end{tabular}

Chapter 28 - Quantz

\begin{tabular}{|l|l|l|l|}
\hline Measure number & Position $(\mathrm{a}, \mathrm{b}, \mathrm{c} \ldots)$ & Interval & Comments \\
\hline 1 & A & P8 & \\
\hline 1 & B & M3 & \\
\hline 1 & C & m3 & \\
\hline 2 & A & m6 & \\
\hline 2 & B & Dim5 & \\
\hline 2 & C & M3 & \\
\hline 2 & D & M3 & \\
\hline 3 & A & m3 & \\
\hline 3 & B & m3 & \\
\hline 3 & C & m7 & \\
\hline 3 & D & M3 & \\
\hline 3 & E & M3 & \\
\hline 4 & A & m3 & \\
\hline 4 & B & m3 & \\
\hline 4 & C & m7 & \\
\hline 4 & D & M3 & \\
\hline 5 & A & M3 & \\
\hline 5 & B & Aug4 & \\
\hline 5 & C & m6 & \\
\hline
\end{tabular}




\begin{tabular}{|c|c|c|c|}
\hline 6 & $\mathrm{~A}$ & M3 & \\
\hline 6 & B & Aug4 & \\
\hline 6 & C & $\mathrm{m} 6$ & \\
\hline 6 & $\mathrm{D}$ & m3 & \\
\hline 7 & A & Dim5 & \\
\hline 7 & $\mathrm{~B}$ & M3 & \\
\hline 7 & $\mathrm{C}$ & P5 & \\
\hline 7 & $\mathrm{D}$ & \begin{tabular}{|l|l} 
P8 \\
\end{tabular} & \\
\hline 8 & $\mathrm{~A}$ & M6 & \\
\hline 8 & B & M6 & \\
\hline 8 & C & P5 & \\
\hline 8 & $\mathrm{D}$ & m3 & \\
\hline 9 & $\mathrm{~A}$ & m3 & \\
\hline 10 & $\mathrm{~A}$ & m3 & \\
\hline 11 & $\mathrm{~A}$ & Dim5 & \\
\hline 11 & B & M3 & \\
\hline 11 & C & M6 & \\
\hline 11 & $\mathrm{D}$ & P5 & \\
\hline 11 & $E$ & Dim5 & \\
\hline 12 & $\mathrm{~A}$ & m3 & \\
\hline 12 & $\mathrm{~B}$ & P4 & \\
\hline 12 & $\mathrm{C}$ & M3 & \\
\hline 13 & $\mathrm{~A}$ & $\mathrm{~m} 6$ & \\
\hline 13 & $\mathrm{~B}$ & Dim5 & \\
\hline 13 & $\mathrm{C}$ & $\mathrm{m} 3$ & \\
\hline 14 & A & $\mathrm{m} 6$ & \\
\hline 14 & B & Dim5 & \\
\hline 14 & $\mathrm{C}$ & m3 & \\
\hline 15 & $\mathrm{~A}$ & m3 & \\
\hline 15 & $\mathrm{~B}$ & P5 & \\
\hline 15 & $\mathrm{C}$ & M3 & \\
\hline 15 & $\mathrm{D}$ & m3 & \\
\hline 15 & $E$ & M3 & \\
\hline 15 & $\mathrm{~F}$ & m3 & \\
\hline 16 & $\mathrm{~A}$ & m3 & \\
\hline 16 & B & M6 & \\
\hline 16 & $\mathrm{C}$ & P5 & \\
\hline 16 & $\mathrm{D}$ & P8 & \\
\hline 17 & $\mathrm{~A}$ & Dim5 & \\
\hline 17 & B & m3 & \\
\hline 18 & $\mathrm{~A}$ & Dim5 & \\
\hline 18 & B & M3 & \\
\hline 19 & A & M3 & \\
\hline 19 & B & m3 & \\
\hline 19 & $\mathrm{C}$ & m3 & \\
\hline 19 & $\mathrm{D}$ & M3 & \\
\hline 20 & $\mathrm{~A}$ & M6 & \\
\hline 20 & $\mathrm{~B}$ & P8 & \\
\hline 20 & $\mathrm{C}$ & M3 & \\
\hline 20 & $\mathrm{D}$ & Dim5 & \\
\hline 20 & $E$ & M3 & \\
\hline 21 & A & P8 & \\
\hline 21 & B & M3 & \\
\hline
\end{tabular}




\begin{tabular}{|c|c|c|c|}
\hline 21 & $\mathrm{C}$ & $\mathrm{m} 3$ & \\
\hline 22 & A & $\mathrm{m} 6$ & \\
\hline 22 & B & Dim5 & \\
\hline 22 & $\mathrm{C}$ & M3 & \\
\hline 22 & $\mathrm{D}$ & M6 & \\
\hline 23 & A & $\mathrm{m} 7$ & \\
\hline 23 & B & $\mathrm{m} 6$ & \\
\hline 23 & $\mathrm{C}$ & $\mathrm{m} 7$ & \\
\hline 23 & D & $\mathrm{m} 3$ & \\
\hline 24 & A & $\mathrm{m} 7$ & \\
\hline 24 & B & M3 & \\
\hline 24 & $\mathrm{C}$ & M7 & \\
\hline 24 & $\mathrm{D}$ & M6 & \\
\hline 24 & $E$ & P5 & \\
\hline 25 & A & Aug4 & \\
\hline 25 & B & $\mathrm{m} 6$ & \\
\hline 25 & $\mathrm{C}$ & P8 & \\
\hline 25 & D & M6 & \\
\hline 25 & $E$ & P5 & \\
\hline 25 & $\mathrm{~F}$ & P8 & \\
\hline 25 & $\mathrm{G}$ & P8 & \\
\hline 26 & $\mathrm{~A}$ & M3 & \\
\hline 26 & B & Dim5 & \\
\hline 26 & $\mathrm{C}$ & M3 & \\
\hline 26 & $\mathrm{D}$ & P8 & \\
\hline 27 & A & M3 & \\
\hline 27 & B & Dim5 & \\
\hline 27 & $\mathrm{C}$ & M3 & \\
\hline 27 & $\mathrm{D}$ & $\mathrm{m} 6$ & \\
\hline 28 & $\mathrm{~A}$ & P5 & \\
\hline 28 & B & M6 & \\
\hline 28 & $\mathrm{C}$ & P5 & \\
\hline 28 & $\mathrm{D}$ & M6 & \\
\hline 29 & A & P5 & \\
\hline 29 & B & $\mathrm{m} 6$ & \\
\hline 29 & $\mathrm{C}$ & Dim5 & \\
\hline 29 & $\mathrm{D}$ & $\mathrm{m} 6$ & \\
\hline 29 & $E$ & Dim5 & \\
\hline 30 & A & M3 & \\
\hline 30 & B & Dim5 & \\
\hline 30 & C & M3 & \\
\hline 30 & $\mathrm{D}$ & M6 & \\
\hline 30 & $E$ & P5 & \\
\hline 31 & A & M3 & \\
\hline 31 & B & $\mathrm{m} 3$ & \\
\hline 31 & $\mathrm{C}$ & $\mathrm{m} 3$ & \\
\hline 31 & D & M3 & \\
\hline 31 & $E$ & M6 & \\
\hline 31 & $\mathrm{~F}$ & Aug4 & \\
\hline 31 & $\mathrm{G}$ & $\mathrm{m} 6$ & \\
\hline 31 & $\mathrm{H}$ & $\mathrm{m} 3$ & \\
\hline 32 & A & M3 & \\
\hline 32 & B & P8 & \\
\hline
\end{tabular}




\begin{tabular}{|l|l|l|l|}
\hline 32 & C & M6 & \\
\hline 32 & D & P5 & \\
\hline 32 & E & P8 & \\
\hline
\end{tabular}

Chapter 29 - Galeazzi

\begin{tabular}{|c|c|c|c|}
\hline Measure number & Position (a,b,c...) & Interval & Comments \\
\hline 1 & A & P8 & \\
\hline 1 & B & M3 & \\
\hline 2 & $\mathrm{~A}$ & P5 & \\
\hline 2 & B & M3 & \\
\hline 2 & $\bar{C}$ & $\mathrm{~m} 6$ & \\
\hline 3 & $\mathrm{~A}$ & M3 & \\
\hline 3 & B & Aug4 & \\
\hline 3 & $\bar{C}$ & $\mathrm{~m} 6$ & \\
\hline 4 & $\mathrm{~A}$ & $\mathrm{~m} 6$ & \\
\hline 4 & B & m7 & \\
\hline 5 & $\mathrm{~A}$ & P5 & \\
\hline 5 & $B$ & P8 & \\
\hline 5 & $\mathrm{C}$ & M6 & \\
\hline 6 & $\mathrm{~A}$ & m3 & \\
\hline 6 & B & M3 & \\
\hline 6 & $\mathrm{C}$ & P8 & \\
\hline 7 & $\mathrm{~A}$ & M3 & \\
\hline 8 & $\mathrm{~A}$ & $\mathrm{P} 4$ & \\
\hline 8 & B & M3 & \\
\hline 9 & $\mathrm{~A}$ & P8 & \\
\hline 10 & $\mathrm{~A}$ & M3 & \\
\hline 12 & A & m3 & \\
\hline 14 & $\mathrm{~A}$ & m3 & \\
\hline 15 & $\mathrm{~A}$ & M3 & \\
\hline 17 & A & M3 & \\
\hline 18 & $\mathrm{~A}$ & M3 & \\
\hline 18 & B & $\mathrm{m} 6$ & \\
\hline 18 & $\mathrm{C}$ & Dim5 & \\
\hline 19 & $\mathrm{~A}$ & M3 & \\
\hline 20 & A & M3 & \\
\hline 20 & B & $\mathrm{m} 6$ & \\
\hline 20 & $\mathrm{C}$ & Dim5 & \\
\hline 21 & A & M3 & \\
\hline 21 & B & $\mathrm{m} 3$ & \\
\hline 23 & $\bar{A}$ & P8 & \\
\hline 23 & B & M6 & \\
\hline 23 & $\bar{C}$ & P5 & \\
\hline 24 & $\mathrm{~A}$ & P8 & \\
\hline 24 & B & $\mathrm{m} 7$ & \\
\hline 25 & A & $\mathrm{m} 6$ & \\
\hline 25 & $B$ & M7 & \\
\hline 26 & $\mathrm{~A}$ & P8 & \\
\hline 26 & B & $\mathrm{m} 7$ & \\
\hline 27 & $\mathrm{~A}$ & M6 & \\
\hline 27 & B & M7 & \\
\hline 28 & $\mathrm{~A}$ & P8 & \\
\hline 30 & $\mathrm{~A}$ & Aug2 & \\
\hline
\end{tabular}




\begin{tabular}{|c|c|c|c|}
\hline 30 & $\mathrm{~B}$ & M3 & \\
\hline 30 & $\mathrm{C}$ & Aug4 & \\
\hline 30 & $\mathrm{D}$ & M6 & \\
\hline 32 & $\mathrm{~A}$ & Aug2 & \\
\hline 32 & B & M3 & \\
\hline 32 & $\mathrm{C}$ & Aug4 & \\
\hline 32 & $\mathrm{D}$ & $\mathrm{m} 6$ & \\
\hline 33 & A & Dim5 & \\
\hline 34 & A & M3 & \\
\hline 36 & $\mathrm{~A}$ & Aug6 & \\
\hline 37 & A & P8 & \\
\hline 38 & A & Aug4 & \\
\hline 39 & A & M6 & \\
\hline 40 & A & $\mathrm{m} 6$ & \\
\hline 40 & B & P5 & \\
\hline 41 & A & P8 & \\
\hline 42 & A & P8 & \\
\hline 42 & B & M3 & \\
\hline 43 & A & P5 & \\
\hline 43 & B & M3 & \\
\hline 43 & C & $\mathrm{m} 6$ & \\
\hline 44 & A & M3 & \\
\hline 44 & B & Aug4 & \\
\hline 44 & C & $\mathrm{m} 6$ & \\
\hline 45 & A & $\mathrm{m} 6$ & \\
\hline 45 & $\mathrm{~B}$ & $\mathrm{~m} 7$ & \\
\hline 46 & $\mathrm{~A}$ & P5 & \\
\hline 48 & $\mathrm{~A}$ & P8 & \\
\hline 48 & B & $\mathrm{m} 6$ & \\
\hline 48 & C & Dim5 & \\
\hline 49 & A & M3 & \\
\hline 50 & A & $\mathrm{m} 6$ & \\
\hline 50 & B & $\mathrm{m} 3$ & \\
\hline 50 & C & $\mathrm{m} 7$ & \\
\hline 51 & A & M6 & \\
\hline 51 & B & M6 & \\
\hline 51 & C & P8 & \\
\hline 51 & D & M3 & \\
\hline 51 & E & Dim5 & \\
\hline 52 & A & M3 & \\
\hline 53 & A & M3 & \\
\hline 54 & A & M3 & \\
\hline 54 & B & $\mathrm{m} 6$ & \\
\hline 54 & $\mathrm{C}$ & Dim5 & \\
\hline 55 & A & M3 & \\
\hline 56 & A & M3 & \\
\hline 56 & B & M2 & \\
\hline 56 & C & $\mathrm{m} 6$ & \\
\hline 56 & D & Dim5 & \\
\hline 57 & A & M3 & \\
\hline 57 & B & P8 & \\
\hline 57 & $\mathrm{C}$ & P8 & \\
\hline 58 & A & P8 & \\
\hline
\end{tabular}




\begin{tabular}{|l|l|l|l|}
\hline 58 & B & P8 & \\
\hline 59 & A & m6 & \\
\hline 59 & B & P8 & \\
\hline 59 & C & M6 & \\
\hline 59 & D & P5 & \\
\hline 60 & A & P8 & \\
\hline 60 & B & m7 & \\
\hline 61 & A & M6 & \\
\hline 61 & B & M7 & \\
\hline 62 & A & P8 & \\
\hline 62 & B & m7 & \\
\hline 63 & A & M6 & \\
\hline 63 & B & M7 & \\
\hline 64 & A & P8 & \\
\hline
\end{tabular}

APPENDIX B:

ANALYSIS OF GJERDINGEN'S (2007) SOPRANO SCALE-DEGREE ANNOTATIONS

CHAPTER FIVE SOMIS

151565436543 3b 365432

CHAPTER EIGHT DITTERSDORF

12365434343176217

CHAPTER TEN HAYDN SONATA (theme only)

174365443431743654

CHAPTER TWELVE - GLUCK SONATA

1517436543671671654321321717151654365436543171321654321

CHAPTER FIFTEEN GALUPPI GRAVE SOSTENUTO

17436543 6b543b $654343 b 43543$ 6b543b 65436715143215671567156715671 6b543b 6b543 5143b21

$71174354336 b 543 b 65436 b 543 b 6543671514321321$

CHAPTER SEVENTEEN DITTERSDORF QUINTET

$\begin{array}{lllllllllllllll}1231231236543165431651 & 43543171543 & 17 & 171 & 5246427 & 5 & 53 & 53 & 5 & 7 & 4 & 7 & 4 & 5\end{array}$ 2464275123123123654316543165116543165143171543171543171543171543

CHAPTER NINETEEN - J.C. BACH ANDANTE

$\begin{array}{llllllll}5432173217165432 & 51743 & 3217 & 5432171 & 5432171351351352156715671 & 543217532171 & 6 b 546 b 43 b\end{array}$ $6546543654323254321716543543217135135135235217 b 6717 b 671$

CHAPTER TWENTY-ONE LEDUC CANTABILE

34343654\#434\#43246175436426426173232323217617321316434321 3b43b43b 617 543b171543b171 43b $43654324246174 \# 57245134343654 \# 434 \# 4324617332323173213164343214321$

CHAPTER TWENTY-TWO LEO

6517432143654326543265432321651743651743243434314365432654326543216543211743243 43b $4365217434343 b 6 b 543143436543265432654322174321$ 123b 6b 6b543b2 6b543b2 3b21 65174321

CHAPTER TWENTY-THREE GALUPPI ARIA

51565432321515654326543643212427654321743 b 1743321765431413214321 


\section{CHAPTER TWENTY-FOUR JOMMELLI}

$516543216543654321516543265436543215656 b 56 b 7153217 b 6565432156 b 7156 b 713217 b 6565432432$ $654321617617143 b 43516543215165432143436743 b 17173217 b 6565432143433217 b 6565432$ 432432165436176171

13513553432 43b 43543543543 43b 435432154343543543 43b 43543543323211462214

\section{CHAPTER TWENTY-SIX MOZART}

654365432646171717654324623211743 b 1743b 6b543b 6543654365432646171717654326321

Note: the Meyer schema in mm. thirty-five to thirty-seven was interpreted as moved to the bass (invertible counterpoint), in parallelism with measures thirty-one through thirty-three.

\section{CHAPTER TWENTY-EIGHT QUANTZ}

$13243654365436716714321123 b$ 23b 432 43b17 543b 543b 6b176b543b21 43b 43654324617

132436543217143211743174312345434326543271434321

\section{CHAPTER TWENTY-NINE GALEAZZI}

$\begin{array}{llllllllllll}135317146531316171 & 6543 & 3754375431 & 43217 b 6717 b 671 & 71 & 71 & 17 & 4 \# 5 & 71 & 3 b 21 & 1353171465 & 6543\end{array}$ $642461737543765431642143217 b 6717 b 671$

\section{APPENDIX C: MUSICAL EXAMPLES}

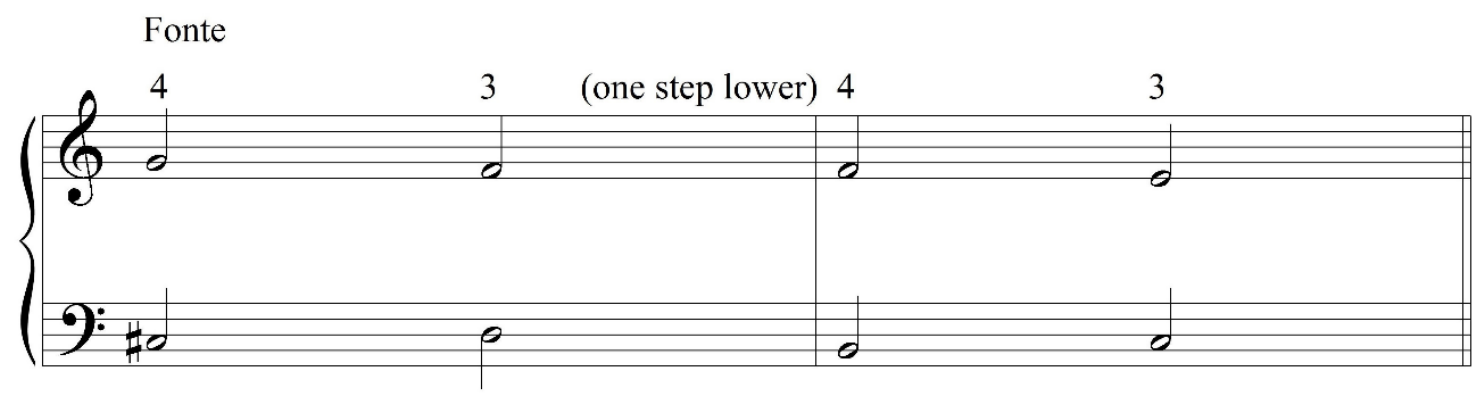

Fonte (monotonal approach)

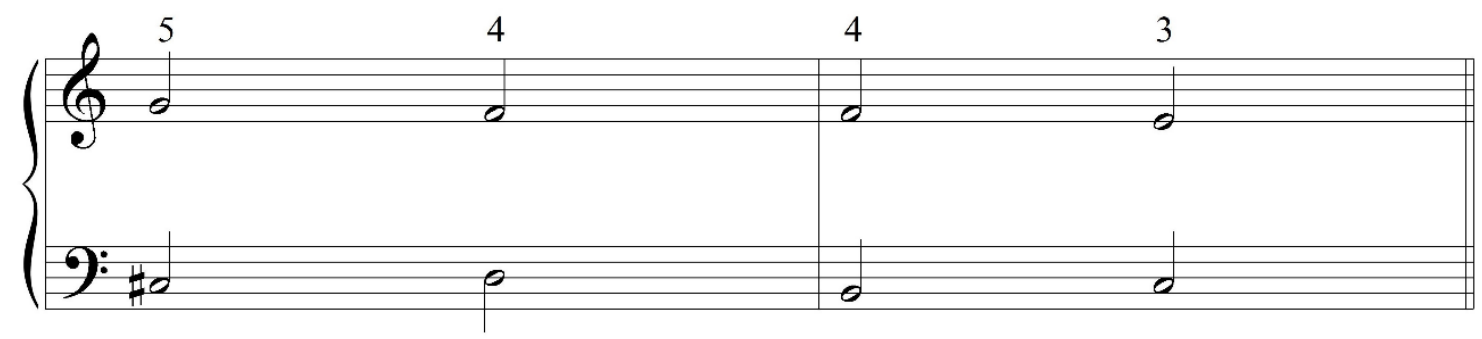

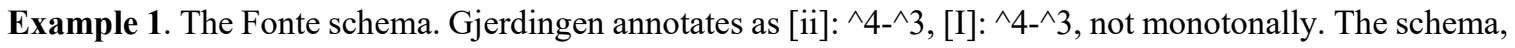
like many additional schemata, serves as an outer-voice contrapuntal skeleton for surface musical activity. 


\section{APPENDIX D}

\begin{tabular}{|c|c|c|c|c|c|c|c|c|c|}
\hline SCHEMA & $\wedge 7$ & $\wedge 1$ & $\wedge 2$ & $\wedge 3$ & $\wedge 4(\# 4)$ & $\wedge 5$ & $\wedge 6$ & $(7 b)^{\wedge} 7$ & $\wedge 1$ \\
\hline Romanesca & & $\begin{array}{l}{ }^{*} \rightarrow \ldots \\
\mid \ldots\end{array}$ & & & & $\ldots \leftarrow$ & & & \\
\hline Comma & & & & 1 & $\leftarrow^{*}$ & $(\leftarrow)$ & & & \\
\hline Sol-Fa-Mi & & & & 1 & $\leftarrow$ & $\leftarrow^{*}$ & & & \\
\hline Fonte & & & & 1 & $\leftarrow$ & $\leftarrow^{*}$ & & & \\
\hline Prinner & & & & 1 & $\leftarrow$ & $\leftarrow$ & $\leftarrow^{*}$ & & \\
\hline Meyer &.$\leftarrow$ & $\leftarrow^{*}$ & & 1 & $\leftarrow$. & & & & \\
\hline Fenaroli & $\ldots \rightarrow$ & 1 & & $\ldots \leftarrow$ & $\leftarrow^{*}$ & & & & \\
\hline Pastorella & & &..$\leftarrow$ & $\leftarrow^{*} \mid$ & $\leftarrow$. & & & & \\
\hline Aprile & $\ldots \leftarrow$ & $\leftarrow^{*}$ & $\leftarrow \ldots$ & & & & & & \\
\hline Jupiter & & $* \rightarrow$ & $\rightarrow \ldots$ & 1 & $\leftarrow$. & & & & \\
\hline Mod. Prin. & 1 & $\leftarrow$ & $\leftarrow$ & $\leftarrow^{*}$ & & & & & \\
\hline Monte & & & & & & & $\ldots \leftarrow$ & $\leftarrow b^{*} \mid$ & $\leftarrow \ldots$ \\
\hline Converging 1 & 1 & $\leftarrow$ & $\leftarrow *$ & $(\leftarrow)$ & & & & & \\
\hline Converging 2 & & & & $\leftarrow$ & $\leftarrow$ & $(\leftarrow)$ & & & \\
\hline Indugio $\dagger$ & 1 & $\leftarrow$ & $\leftarrow *$ & $(\leftarrow)$ & & & & & \\
\hline Jommelli & & & & & & 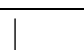 & $\leftarrow^{*}$ & & \\
\hline [Heartz-Rice] & & & & & & $* \rightarrow$ & $\leftarrow$ & & \\
\hline $\begin{array}{l}\text { Mi-Re-Do / } \\
\text { Cudworth }\end{array}$ & & | & $\leftarrow$ & $\leftarrow$ & $\leftarrow^{*}$ & $(\leftarrow)$ & $(\leftarrow)$ & $(\leftarrow)$ & \\
\hline Do-Si-Do & $\rightarrow$ & $\leftarrow$ & $\leftarrow^{*}$ & $(\leftarrow)$ & & & & & \\
\hline $\begin{array}{l}\text { Grand } \\
\text { Cadence }\end{array}$ & & 1 & $\leftarrow \ldots$ & & & $\ldots \leftarrow$ & $\leftarrow \ldots$ & & $\ldots \leftarrow^{*}$ \\
\hline $\mathrm{HC} 1$ & & & 1 & $\leftarrow^{*}$ & & & & & \\
\hline $\mathrm{HC} 2$ & 1 & $\leftarrow^{*}$ & & & & & & & \\
\hline Quiesc. 1 & & & & & & & $\ldots \leftarrow$ & $\begin{array}{l}\leftarrow b^{*} \\
\ldots \rightarrow\end{array}$ & I \\
\hline Quiesc. 2 & & & & & & $* \rightarrow$ & $\rightarrow$ & $\rightarrow$ & 1 \\
\hline $\begin{array}{l}\text { [Volta/ } \\
\text { Svago- } \\
\text { Mitchell/ } \\
\text { Aerts] }\end{array}$ & & & & | & $\begin{array}{c}* \# \rightarrow \\
\leftarrow \ldots\end{array}$ & $\rightarrow \ldots$ & & & \\
\hline Clausula V. & & & & & & & $(\rightarrow)$ & $* \rightarrow$ & 1 \\
\hline Passo I. & & & & & & & $(\rightarrow)$ & $* \rightarrow$ & 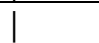 \\
\hline Do-Re-Mi & & $* \rightarrow$ & $\rightarrow$ & & & & & & \\
\hline
\end{tabular}

Diagram 1a. Skeletal soprano scale-degree transitions in galant schemata in a major-mode context

$*=$ start of motion

()$=$ optional prefix before start of motion

I=end of motion

$\ldots=$ move on to next ...

$\mathrm{b} / \sharp=$ sharp or flat version of a scale-degree

/ / $\rightarrow$ [bolded $]=$ scale degrees involved in a semitone motion (in a major-mode context)

$\dagger$ The Indugio adds a polyphonic-melody diminution respective to the Converging Cadence; only the underlying stepwise (Converging Cadence) motion is represented here. 
Bolded schema name $=$ associated with $\wedge$ 4-^ 7 tritone resolution; Prinner may be articulated by $\wedge 7-\wedge 1$ bass (or $\wedge 5-\wedge 1$ bass) at its end, hence assimilated in some sense to the tritone-resolution group of schemata. (Even with bass $\wedge^{\wedge} 2-\wedge 1$, the figured-bass sonorities $7-6$ or variants lead to a matched tritone).

[] $=$ schema not originally proposed in Gjerdingen (2007).

\begin{tabular}{|l|l|l|l|l|l|l|l|l|l|}
\hline SCHEMA & $\wedge 7$ & $\wedge 1$ & $\wedge 2$ & $\wedge 3$ & $\wedge 4(\# 4)$ & $\wedge 5$ & $\wedge 6$ & $(7 b)^{\wedge} 7$ & $\wedge 1$ \\
\hline $\begin{array}{l}\text { Aug. 6 } \\
\text { [Morte- } \\
\text { Rice] }\end{array}$ & & & & & $* \sharp \rightarrow$ & & & & \\
\hline $\begin{array}{l}\text { [Le-sol- } \\
\text { fi-sol- } \\
\text { Byros] }\end{array}$ & 1 & $\leftarrow *$ & & $* b \rightarrow \rightarrow$ & $\rightarrow \# \rightarrow$ & $\mid$ & & & \\
\hline
\end{tabular}

Diagram 1b. Skeletons of schemata that necessitate elements from the parallel minor when embedded in a major-mode context 